\title{
An Insight into Phytochemical, Pharmacological, and Nutritional Properties of Arbutus unedo L. from Morocco
}

\author{
Mohammed El Haouari $\mathbb{D}^{1,2}$ Najat Assem, ${ }^{2}$ Sushil Changan, ${ }^{3}$ Manoj Kumar ${ }^{4},{ }^{4}$ \\ Sevgi Durna Daştan, ${ }^{5,6}$ Jovana Rajkovic, ${ }^{7}$ Yasaman Taheri $\mathbb{D}^{8},{ }^{8}$ and Javad Sharifi-Rad $\mathbb{D}$, 9 \\ ${ }^{1}$ Department of Biology and Earth Sciences, \\ Laboratory of Pedagogical Engineering and Didactics of Sciences and Mathematics (IPDSM), \\ Regional Center for Education Careers and Training (CRMEF Fès-Meknès), B.P: 1178 Taza-Gare, Taza, Morocco \\ ${ }^{2}$ Laboratory of Natural Substances, Pharmacology, Environment, Modeling, Health \& Quality of Life (SNAMOPEQ), \\ Polydisciplinary Faculty of Taza, Sidi Mohamed Ben Abdellah University of Fez, B.P.: 1223 Taza-Gare, Taza, Morocco \\ ${ }^{3}$ Division of Crop Physiology, Biochemistry and Post-Harvest Technology, ICAR-Central Potato Research Institute, \\ Shimla 171001, India \\ ${ }^{4}$ Chemical and Biochemical Processing Division, ICAR-Central Institute for Research on Cotton Technology, \\ Mumbai 400019, India \\ ${ }^{5}$ Department of Biology, Faculty of Science, Sivas Cumhuriyet University, Sivas 58140, Turkey \\ ${ }^{6}$ Beekeeping Development Application and Research Center, Sivas Cumhuriyet University, Sivas 58140, Turkey \\ ${ }^{7}$ Institute of Pharmacology, Clinical Pharmacology and Toxicology, Medical Faculty, University of Belgrade, Belgrade, Serbia \\ ${ }^{8}$ Department of Biosciences, College of Life and Environmental Sciences, University of Exeter, Exeter, UK \\ ${ }^{9}$ Phytochemistry Research Center, Shahid Beheshti University of Medical Sciences, Tehran, Iran \\ ${ }^{10}$ Facultad de Medicina, Universidad Del Azuay, Cuenca, Ecuador
}

Correspondence should be addressed to Mohammed El Haouari; elhouarim@yahoo.fr and Javad Sharifi-Rad; javad.sharifirad@ gmail.com

Received 2 September 2021; Revised 23 October 2021; Accepted 7 November 2021; Published 22 November 2021

Academic Editor: Atul Kabra

Copyright $\odot 2021$ Mohammed El Haouari et al. This is an open access article distributed under the Creative Commons Attribution License, which permits unrestricted use, distribution, and reproduction in any medium, provided the original work is properly cited.

Arbutus unedo L. (Ericaceae) is an evergreen shrub widely distributed in the Mediterranean region, particularly through the Moroccan forests. It is an important medicinal plant of great scientific interest due to its nutritional, pharmacological, and chemical properties. The objective of this review is to provide insights into traditional medicinal uses and phytochemical and pharmacological properties of $A$. unedo from Morocco. In Morocco, the plant has been used as a traditional medicine to treat several pathological conditions. Many phytochemical compounds have been reported in the plant, of which vitamins, carotenoids, flavonoids, polyphenols, tannins, and their derivatives are the most prevalent. Leaves and fruits of $A$. unedo contain the most significant number of phytochemicals among the species. Furthermore, researchers have demonstrated that $A$. unedo exhibited antioxidant, anticancer, antibacterial, antidiabetic, antiaggregant, and antihypertensive activities due to the presence of many biochemical compounds with health-promoting properties. According to different toxicity tests, the use of $A$. unedo is devoid of any significant side effects and/or toxicity. Despite its nutraceutical and health-promoting properties, Moroccan A. unedo remains underexploited mainly, and most of its traditional uses have not yet undergone scientific evidence-based research; therefore, improved knowledge about the potential value of the plant would allow understanding of its biological activity based on its phytochemical compounds that may contribute to the species preservation and valorization. 


\section{Introduction}

During recent years, there has been an increasing reliance on phytonutrients and medicinal plants, due to their wide range significance in human health, food industry, and human nutrition [1-4]. According to the World Health Organization (WHO), $80 \%$ of the world's population depends on traditional medicine for primary health care, especially in Asian and African countries [5]. In fact, various reports from epidemiological studies have consistently shown an inverse association between regular consumption of fruits and vegetables and the risk of cardiovascular diseases (CVD) and certain types of cancer [6-10]. Furthermore, it has been reported that herbal remedies have fewer side effects and are better tolerated by patients than synthetic medications [11]. In addition, the WHO has recognized that traditional medicine is an important component in health care and has been encouraging research on development involving medicinal plants [12]. The health beneficial properties of medicinal plants are in part attributed to the antioxidant activity of their phytochemical compounds, such as phenols, flavonoids, tannins, alkaloids, carotenoids, vitamins, and endogenous metabolites [13-15].

Arbutus unedo (A. unedo), the strawberry tree (Ericaceae), is widely distributed in the Mediterranean region. It can be also found in Canary Islands and western Asia, where climate is adequate to its development $[16,17]$. This fruit tree species is known by different vernacular names, such as sasnou and bakhanou in Morocco, madroño in Spain, arbousier in France, Koumaria in Greek, and corbezzolo in Italy [18].

In Morocco, strawberry trees grow wild in different bioclimatic regions extending from the subhumid to the semiarid regions (Figure 1). A. unedo has been extensively found in the region of the Northwest, Central Plateau, PreRif and Western Rif, High and Middle Atlas, mainly associated with Quercus ilex and sometimes with Pinus halepensis and Tetraclinis articulate. A fragmented-like distribution is common in the Central, Souss plateau, and Northeastern regions. A. unedo shows strong resistance to hard environmental conditions and has the ability to regenerate after forest fires. This plant populations are widespread on all types of substrates but most often on siliceous and calcareous soils at altitudes varying from 150 to $1613 \mathrm{~m}$. The average of annual temperature and rainfall varied from $12.4^{\circ} \mathrm{C}$ to $18.4^{\circ} \mathrm{C}$ and from 337 to $1115 \mathrm{~mm}$, respectively [19].

Traditionally, the fruits, leaves, and roots of $A$. unedo are well-known and used by the Moroccan population as diuretic, astringent, antidiarrheal, antiasthmatic, antiinflammatory, antidiabetic, antihypertensive, against rheumatism and gastrointestinal and renal diseases [20-27]. However, all these uses remain more as traditional habits than having economical purposes.

A diversity of pharmacological properties is ascribed to A. unedo, such as astringent, depurative, anti-inflammatory, haemostatic, antitumor, antioxidant, antimicrobial, spasmolytic, and neuroprotective [28-40].
Furthermore, experimental investigations of our group have shown that $A$. unedo extracts exhibited different biological properties including antioxidant, platelet antiaggregant, vasorelaxant, antihypertensive, and antidiabetic activities [37, 41-49]. In addition, the plant has been shown to contain different phytoconstituents such as flavonoids, tannins, phenolic acids, organic acids, $\alpha$-tocopherol, carotenoids, anthocyanins, triterpenoids, fatty acids, sterols, vitamin $\mathrm{c}$, fibers, calcium $(\mathrm{Ca})$, potassium $(\mathrm{K})$, magnesium $(\mathrm{Mg})$, phosphorus $(\mathrm{P})$, and other bioactive compounds [37, 47, 50-55], which contribute to its various pharmacological and nutritional properties.

In Morocco, no economic importance was attributed to A. unedo, and the plant remains largely underexploited, in comparison to other Mediterranean countries, where the fruit of the Arbutus tree is highly sought after for its nutritional qualities [56-58]. Furthermore, A. unedo tree populations are severely destroyed due to deforestation and overcollecting. In addition, review publications related to A. unedo from other countries can be found in the literature; however, to the best of our knowledge, there are no comprehensive scientific reviews to cover all aspects of information about $A$. unedo grown in Morocco. Thus, an improved knowledge about the potential value of the plant could contribute to enhance the production, marketing, and consumption of $A$. unedo derived products, which may contribute to the species preservation and valorization. In this context, the aim of this work is to provide a comprehensive review concerning the ethnobotanical, pharmacological, nutritional, phytochemical, and toxicological properties of $A$. unedo grown spontaneously in Morocco, which may encourage interested researchers to conduct further investigations to evaluate the health-promising benefits and nutritional properties of Moroccan A. unedo, its active constituents, and their derivatives.

\section{Search Strategy}

Available information was collected from different scientific databases such as PubMed, Science direct, Springer, Web of Science, and Wiley using keywords: Arbutus unedo L., A. unedo L., strawberry tree, ethnobotanical, phytochemical and Pharmacological properties. Additional references were hand-searched. This review is limited to scientific research concerning the ethnobotanical, pharmacological, and phytochemical properties of $A$. unedo L. grown in Morocco.

\section{Botanical Description}

A. unedo belongs to family Ericaceae that is in the major group Angiosperms (flowering plants). It is an evergreen shrub with erect and branched stems (Figure 2). The plant can reach a height of 12 meters, but it is normally a shrub between 1.5 and 3 meters tall [16]. It is an important ornamental bush due to its nice look and fragrance of the white flowers and the red fruit, which appear simultaneously in autumn and winter. The leaves are evergreen, entire, oblonglanceolate, short-stalked, and coriaceous with a dark green color and finely serrated margin [59]. The flowers are 


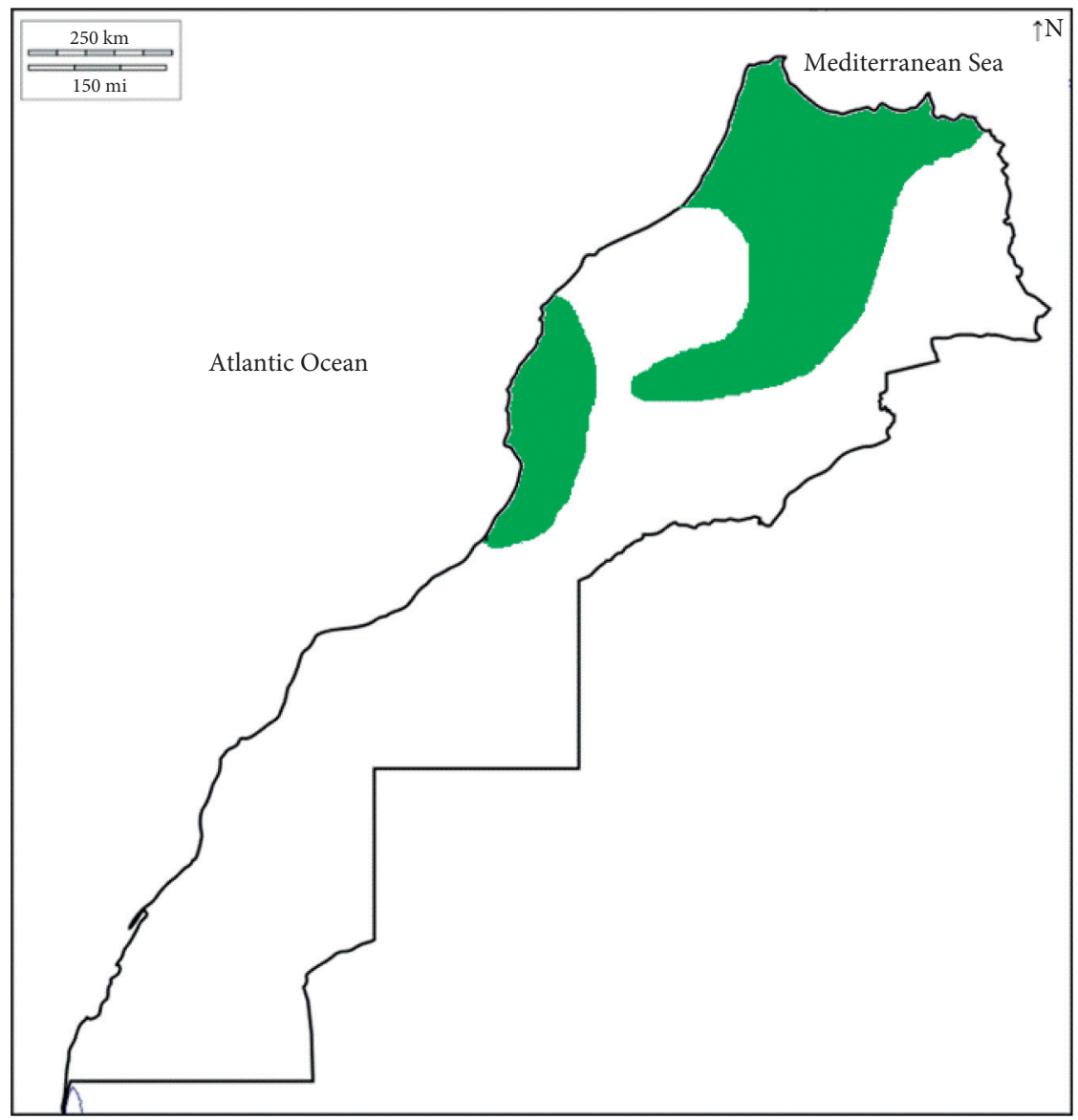

Figure 1: Approximate distribution of Arbutus unedo L. throughout Morocco.
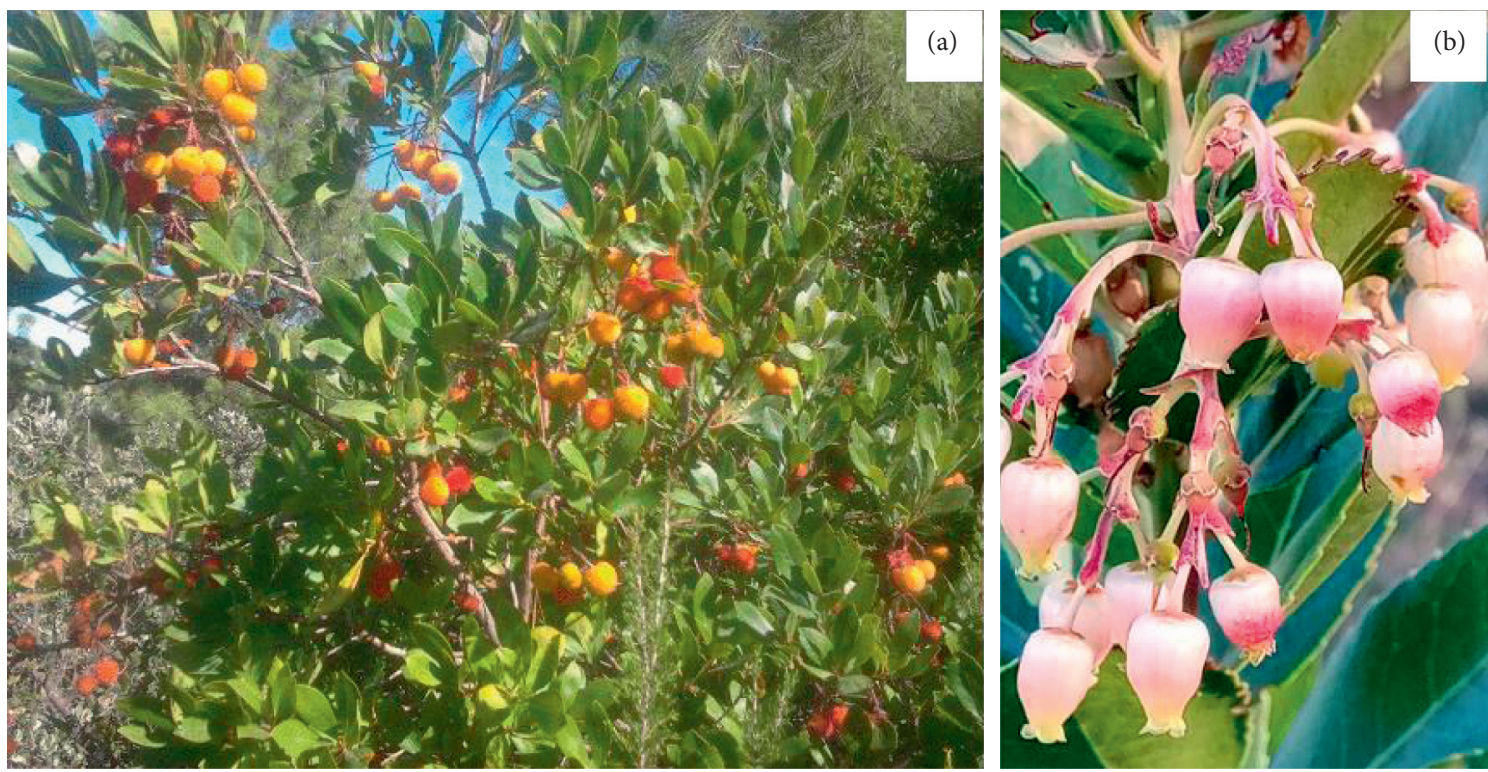

Figure 2: The whole plant (a) and flowers (b) of Arbutus unedo L.

hermaphrodites, fragrant, white, and like little bells, with 5 green sepals fused at the base, 5 united petals, and 10 stamens [18]. A. unedo fruit is a spherical berry about $1-2 \mathrm{~cm}$ in diameter, with a rough surface, green to yellow to bright red when fully ripe. The strawberry tree bears both flowers and fruits at varying degrees of maturity. This is due to the long ripening period of the fruits, which is more than one year [59]. 


\section{Traditional Uses}

In Morocco, different parts of $A$. unedo are used in folk medicine to treat various ailments (Table 1). A survey of medicinal plants in Oriental Morocco showed that A. unedo roots and leaves are widely used in the treatment of hypertension and diabetes [22]. Authors reported that the phytotherapy is widely adopted in northeastern Morocco. About $67.5 \%$ of total identified patients regularly utilized phytotherapy to treat their diseases. In another ethnobotanical survey realized in Northern Morocco, the leaves and the roots of the plant were used traditionally to treat diabetes, hypertension, and cardiac diseases [23]. Furthermore, the roots and cortex of the plant have been also used as a remedy for cholesterol-lowering, against digestive problems and CVD [60]. In another ethnobotanical study, El-Hilaly et al. reported that the leaves and fruits of $A$. unedo are orally administered in the form of decoction as well as raw by the population in the region of Taounate for the treatment of renal diseases [24]. In Ouezzane (North-West of Morocco), the leaves of the plant have been used as decoction in the treatment of diabetes [61]. Other ethnobotanical surveys realized through Morocco revealed that the plant is also used by the population as stomachic, diuretic, astringent, antidiarrheal, antiasthmatic, and anti-inflammatory medicine, and against rheumatism $[20,25,27]$. There are numerous reports, which showed widespread utilization of $A$. unedo to heal various disease conditions in Morocco. Therefore, there is an urgent need to utilize $A$. unedo as an effective alternative to modern allopathy medicines to heal several diseases.

\section{Phytoconstituents}

The plant is also an important source of phytochemical compounds; therefore, many bioactive compounds are isolated. It is revealed that genetic variability and environmental factors may affect the phytochemistry of $A$. unedo. Phytochemicals found in various parts of Moroccan A. unedo are given in Table 2 , and the structures are shown in Figure 3.

5.1. Leaves. A number of phytochemical studies revealed that $A$. unedo leaves contain various classes of chemical compounds such as phenolic compounds, terpenoids, anthocyanins, flavonoids, and tannins. In a previous study, we have demonstrated the presence of genins and heterosidic flavonoids in the extracts of $A$. unedo leaves collected from Tazzeka Mountain (region of Taza) [37]. In another study, we have isolated tannins from $A$. unedo leaf extract [48]. Other phytochemical analysis reported that $A$. unedo leaves contain various polyphenolic compounds, such as epicatechin, catechin, and catechin gallate [47].

In a screening study, Mrabti et al. reported that $A$. unedo leaves from the Beni Mellal region contain tannins, flavonoids, and anthraquinones at high concentrations, and free quinones and terpenoids in lower concentrations. A study of Kachkoul et al. found that $A$. unedo leaf extracts from
Taounate region contain polyphenols, flavonoids, flavonols, and anthocyanins [62]. The level of anthocyanins was low with regard to other compounds. The authors used ultraperformance liquid chromatography (UPLC-PDA-ESI-MS) to characterize the chemical compounds in the leaves. The UPLC profile indicated the presence of 22 compounds of gallic acid derivatives and flavonoids [62]. In another study, it has been reported that hydroalcoholic and aqueous extracts from $A$. unedo leaves contain tannins, polyphenols, and flavonoids [63]. Thus, the consumption of $A$. unedo leaves as raw or decoction would provide a sufficient amount of health-promoting phytochemicals.

5.2. Fruits. Little information is known about the chemical composition of Moroccan A. unedo fruits. Recently, Zitouni and coworkers [64] have analyzed the phenolic compounds in five strawberry tree fruits from different locations in Morocco and found that total phenols varied from 25.37 to $39.06 \mathrm{mg}$ GAE/g D.W, while total flavonoid ranged from 3.30 to $7.07 \mathrm{mg}$ GAE/g D.W. In total, 17 phenolic compounds have been identified in sampled cultivars, of which gallocatechol and catechin were the most abundant.

El Cadi et al. investigated the phytochemical profile of strawberry tree fruits grown in different locations of Northern Morocco (Achakar, Qsar Kbir and ChaounQalaa). Results indicate that the chemical composition of the fruits varied between the three regions. Indeed, fruits from Achakar showed a high amount of polyphenols and flavonoids (127.5 $\pm 7.14 \mathrm{mg}$ GAE/g (w/w) (D.W) and $105.9 \pm 3.2 \mathrm{mg} \mathrm{QE} / \mathrm{g}(\mathrm{w} / \mathrm{w})(\mathrm{D} . \mathrm{W})$, respectively), while berries from Qsar Kbir presented a high content of anthocyanins and tannins $(1.48 \pm 0.09 \mathrm{mg} \mathrm{Pg}-3-\mathrm{glu} / \mathrm{g}(\mathrm{w} / \mathrm{w})$ (D.W) and $1.22 \pm 0.1 \mathrm{mg} \mathrm{EC} / \mathrm{g}(\mathrm{w} / \mathrm{w})(\mathrm{D} . \mathrm{W})$, respectively). In addition, chemical analysis of the three fruits using HPLCDAD-ESI/MS revealed the presence of 75 chemical compounds, including hydroxybenzoic acids, hydroxycinnamic acids, flavone, flavan-3-ols, flavonols, and dihydroflavonols [65]. It was suggested that the variability observed in phytochemical composition among the different fruit extracts could be due to the geographical location of the samples.

In another study, Zitouni et al. determined the content of the total phenolic compounds and flavonoids, condensed and hydrolyzable tannins, and anthocyanins in twelve genotypes of A. unedo fruits collected from different locations of Morocco. Results showed that total phenolic compounds and flavonoids varied from $22.63 \pm 1.74$ to $39.06 \pm 2.44 \mathrm{mg} \mathrm{GAE} / \mathrm{g}$ D.W and from $3.30 \pm 0.60$ to $8.62 \pm 1.10 \mathrm{mg}$ RE/g D.W, respectively, while anthocyanins varied from $0.12 \pm 0.06$ to $0.66 \pm 0.15 \mathrm{mg}$ cya-3glu/100 g D.W; however, condensed tannins and hydrolyzable tannins ranged between $10.41 \pm 1.07-16.08 \pm 1.50 \mathrm{mg} \mathrm{TAE} / \mathrm{g}$ D.W and $4.08 \pm 2.43-6.34 \pm 3.47 \mathrm{TAE} / \mathrm{g}$ D.W, respectively. Using the HPLC assay, the authors also identified 17 phenolic compounds in the studied fruits, of which gallocatechol and catechin were the most abundant [66]. It was concluded that genetic factors seem to be responsible for the chemical profile of the analyzed fruits. The significant amounts of phytochemicals in A. unedo fruits confirm the nutritional and medicinal value of the plant. 
Table 1: Traditional uses of $A$. unedo L. in Morocco.

\begin{tabular}{|c|c|c|c|}
\hline Part used & Traditional medicinal uses & Mode of preparation/administration & References \\
\hline Leaves & $\begin{array}{c}\text { Kidney diseases } \\
\text { Antidiabetic, antihypertensive } \\
\text { Cardiac disease, diabetes, hypertension } \\
\text { Antidiabetic, astringent, antidiarrheal } \\
\text { Stomachic, antiasthmatic }\end{array}$ & $\begin{array}{l}\text { Decoction } \\
\text { Decoction/infusion } \\
\text { N.D. } \\
\text { Decoction } \\
\text { Decoction }\end{array}$ & $\begin{array}{l}{[24]} \\
{[22,108]} \\
{[23]} \\
{[25,26,61]} \\
{[27]}\end{array}$ \\
\hline Roots & $\begin{array}{c}\text { Antidiabetic, antihypertensive, anti-inflammatory, against rheumatism } \\
\text { Cardiac disease, diabetes } \\
\text { Cholesterol-lowering, digestive problems, cardiovascular diseases } \\
\text { Diabetes } \\
\text { Stomachic, antiasthmatic }\end{array}$ & $\begin{array}{l}\text { Decoction/infusion } \\
\text { N.D. } \\
\text { Decoction } \\
\text { Decoction } \\
\text { Decoction }\end{array}$ & $\begin{array}{c}{[22,25,108]} \\
{[23]} \\
{[60]} \\
{[26]} \\
{[20,27]}\end{array}$ \\
\hline Fruits & $\begin{array}{c}\text { Kidney diseases } \\
\text { Digestive diseases and diarrhea }\end{array}$ & $\begin{array}{l}\text { Raw } \\
\text { Infusion, fresh fruit }\end{array}$ & $\begin{array}{c}{[24]} \\
{[19,21]}\end{array}$ \\
\hline Bark & $\begin{array}{c}\text { Cholesterol-lowering, digestive problems, cardiovascular diseases } \\
\text { Diuretic, astringent, antidiarrheal }\end{array}$ & $\begin{array}{l}\text { Decoction } \\
\text { Decoction }\end{array}$ & $\begin{array}{l}{[60]} \\
{[25]}\end{array}$ \\
\hline
\end{tabular}

N.D: not determined.

TABLE 2: Major phytochemical compounds reported from A. unedo $L$.

\begin{tabular}{|c|c|c|c|}
\hline $\begin{array}{l}\text { Plant } \\
\text { part }\end{array}$ & Major components & Extraction method & References \\
\hline \multirow{10}{*}{ Leaves } & & Solid-liquid extraction & \\
\hline & Genins and heterosidic flavonoids & Colorimetric method & [37] \\
\hline & & Soxhlet extraction method & \\
\hline & Tannins & Soxhlet extraction method & {$[47,48]$} \\
\hline & $\begin{array}{l}\text { Arbutoside, quercetin, epicatechin, catechin, catechin gallate, hyperoside and } \\
\text { gallic acid }\end{array}$ & $\begin{array}{l}\text { HPLC coupled with mass } \\
\text { spectrometry }\end{array}$ & [47] \\
\hline & Tannins, flavonoids, anthraquinones, terpenoids, free quinones & $\begin{array}{l}\text { Colorimetric method } \\
\text { Infusion }\end{array}$ & {$[67]$} \\
\hline & Polyphenols, flavonoids, tannins. & Soxhlet extraction method & {$[63]$} \\
\hline & & Colorimetric method & \\
\hline & Phenolic compounds, flavonoids, flavonols, and anthocyanins & $\begin{array}{l}\text { Colorimetric method and UPLC- } \\
\text { PDA-ESI-MS }\end{array}$ & {$[66]$} \\
\hline & Gallic acid derivatives and flavonoids (22 compounds) & & \\
\hline \multirow[b]{2}{*}{ Roots } & Tannins, flavonoids, anthraquinones, terpenoids, free quinones & Colorimetric method & {$[67]$} \\
\hline & Catechin & $\begin{array}{l}\text { XAD-16 resin } \\
\text { HPLC }\end{array}$ & {$[50]$} \\
\hline
\end{tabular}

Flavonoids, tannins, anthocyanins, anthraquinones, sterols, steroids, deoxysugars, and glycosides

75 compounds identified as hydroxybenzoic acids, hydroxycinnamic acids, flavone, flavan-3-ols, flavonols, and dihydroflavonols.

Fruit

Phenols, flavonoids, condensed tannins, hydrolyzable tannins, and anthocyanins.

17 phenolic compounds, of which gallocatechol and catechin were the most abundant
Colorimetric method

HPLC

UPLC-PDA-ESI-MS

Spectrophotometric methods

HPLC

UPLC-PDA-ESI-MS, Ultra-performance liquid chromatography with photodiode array and electrospray ionization tandem mass spectrometry; HPLC, highperformance liquid chromatography.

5.3. Roots. There are few studies that have focused on the chemical composition of the Moroccan A. unedo roots. Using Zippertex technology, Mrabti et al. isolated catechin (the therapeutic active compound) from A. unedo roots (Figure 4). The chemical structure of this compound was characterized by MS and NMR $\left({ }^{1} \mathrm{H}\right.$ and $\left.{ }^{13} \mathrm{C}\right)$ analyses [50]. In addition, similar to leaves, the roots of $A$. unedo were shown also to contain tannins, anthraquinones, and flavonoids [67]. Furthermore, scientific investigations are needed to unearth the phytochemical profile of $A$. unedo roots and its applications to treat several diseases.

\section{Nutritional Characterization}

The berries of $A$. unedo are popular in Morocco and consumed by the population as food since a long time, while the leaves and roots are commonly used for medicinal applications to treat ailments. The fruits have a sweet taste and contain a wide variety of molecules with an excellent nutritional quality including phenolic compounds, sugars, dietary fiber, $\alpha$-tocopherol, proteins, unsaturated fatty acids, organic and phenolic acids, arbutine, vitamins, and carotenoids [56, 57, 68-71]. 


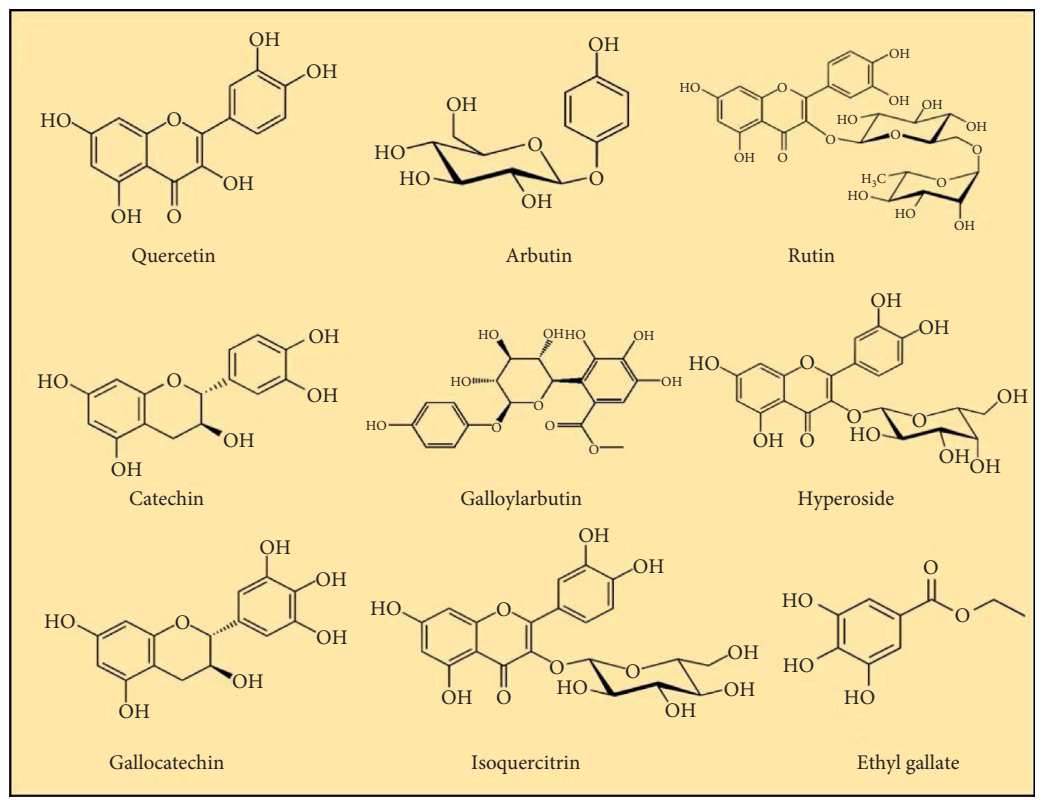

(a)

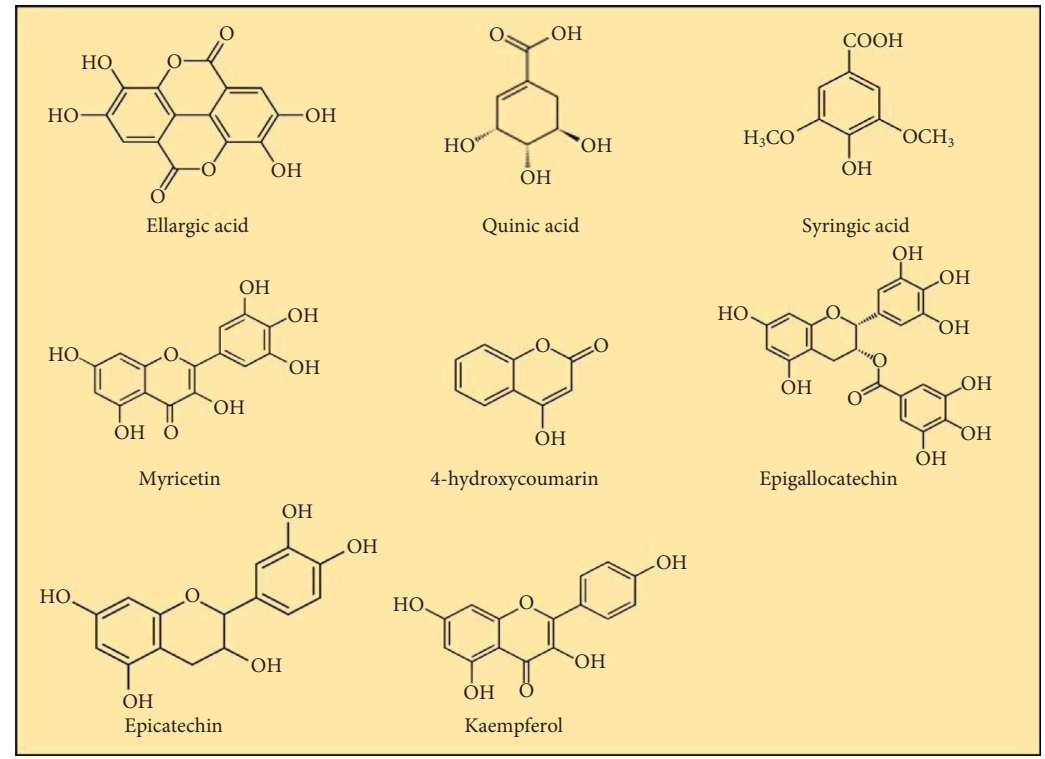

(b)

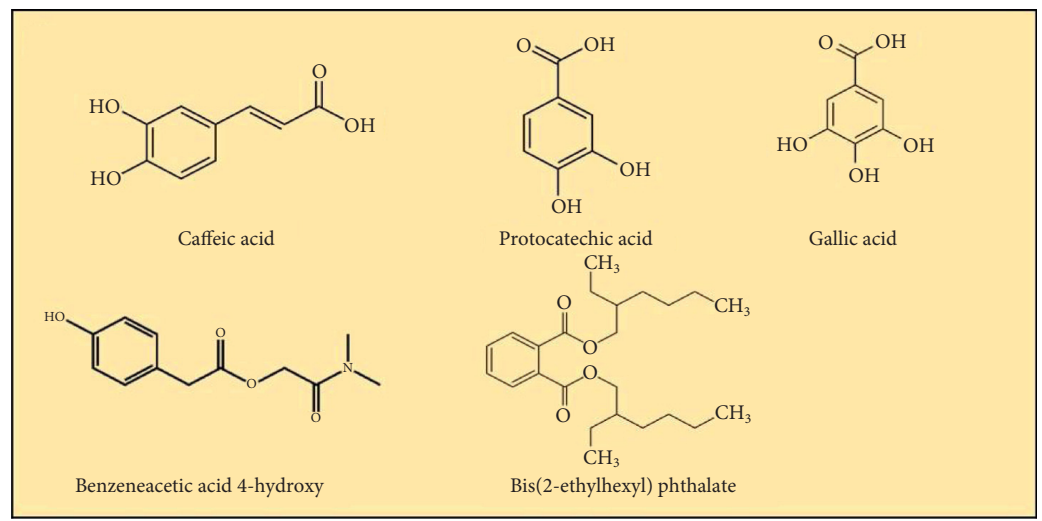

(c)

FIGURE 3: Structure of various bioactive compounds present in leaves, roots, and fruits of strawberry trees. 


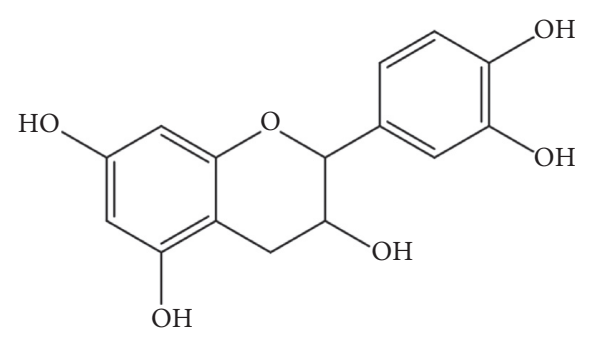

FIgUre 4: Chemical structure of catechin isolated from A. unedo roots [50].

In Morocco, ripened fruits of $A$. unedo are eaten as a remedy for some health problems such as gastrointestinal, infective, and urological diseases [21, 24]. Their consumption provides the body with a significant amount of nutrients, vitamins, minerals, sugars, and other bioactive compounds with health beneficial effects. The fruits are not consumed very often, but they can be enjoyed when eaten in moderate quantities. However, if taken in excess, on fasting, they would be purgative. They are usually eaten in the field as fresh fruits and sometimes taken home for dessert or sold by rural people at the weekly markets or by the roadside in small drum or reed baskets. Often this product constitutes a complement to rural income.

A study by El Cadi et al. demonstrated that A. unedo fruits collected from different parts of Morocco are with high antioxidant capacity. It has been concluded that this fruit is a source of various potentially therapeutic compounds for the treatment of many diseases [65]. In addition, several studies reported that $A$. unedo leaves constitute valuable flavonoids and minerals, especially $\mathrm{K}, \mathrm{Ca}, \mathrm{P}$, and $\mathrm{Mg}[47,67]$. It was suggested that the rich mineral and polyphenols content of A. unedo leaves can constitute an interesting addition to human diet and therapy.

Despite its high nutritional value, strawberry fruit valuation is still timid in Morocco and is limited to the production of honey, jams, and pastries by some cooperatives located in the Western Rif of Morocco [19].

\section{Pharmacological Activities}

The documented pharmacological activities of Moroccan A. unedo, its extracts, and compounds isolated from this species are detailed below and are summarized in Table 3, and some of the pharmacological effects are illustrated in Figure 5.

7.1. Antidiabetic Activity. Type 2 diabetes mellitus (DM) is a complex syndrome characterized by chronic hyperglycemia as a consequence of a disorder of insulin secretion, insulin resistance/action, or combination of both of these factors. It is estimated that $25 \%$ of the world population is affected by this disease [72]. Furthermore, DM is considered as the major risk factor for CVD including heart ischemic disease, stroke, atherosclerosis, and heart failure [73]. Therefore, the identification of natural antidiabetic compounds with insignificant toxicity and no side effects is of great interest [74].
In this regard, several medicinal plants have been used traditionally for the treatment and/or prevention of DM [75].

The antidiabetic activity of $A$. unedo roots extract has been tested in rats using the oral glucose tolerance test (OGTT) and the intravenous glucose tolerance test (IVGTT). Oral administration $(500 \mathrm{mg} / \mathrm{Kg} \mathrm{b.w})$ of the extract to rats submitted to OGTT produced a significant decrease in glycaemia after glucose overload. This effect was not confirmed by the IVGTT. Furthermore, $A$. unedo extract exhibited significant reduction of intestinal glucose absorption, which may justify in part the reduction of glycaemia observed in the OGTT model [41].

In a pre-clinical study, it has been demonstrated that the oral administration of water extracts from $A$. unedo roots $(400 \mathrm{mg} / \mathrm{L}$, drink water) showed significant reduction of glycaemia in neonatal streptozotocin (n-stz)-induced diabetic rats under chronic treatment [46]. Furthermore, the authors reported that the combination of the plant extract with insulin enhanced the peripheral utilization of glucose and potentiated the activity of insulin, which may explain in part the hypoglycemic effect observed with the in vivo test [46]. It is concluded that $A$. unedo roots contain bioactive compounds, which contribute to their antidiabetic activity and validate their utilization in traditional medicine.

In another study, Mrabti et al. assessed the antidiabetic properties of $A$. unedo root extract in vitro and in vivo. In the in vitro test, results showed that $A$. unedo root extract exerted more potent inhibitory effect against $\alpha$-glucosidase than acarbose (positive control) with $\mathrm{IC}_{50}$ (median inhibitory concentration) values of $94.81 \pm 5.99 \mu \mathrm{g} / \mathrm{mL}$ and $199.53 \pm 1.12 \mu \mathrm{g} / \mathrm{mL}$ respectively. In the in vivo antidiabetic study, it has been found that $A$. unedo extract $(500 \mathrm{mg} / \mathrm{Kg}$ b.w) produced a significant decrease in glycaemia similar to that of metformin (positive control) in STZ-NA induceddiabetic mice after chronic oral administration for 4 weeks. In addition, treatment with the extract $(500 \mathrm{mg} / \mathrm{day} / \mathrm{kg} \mathrm{b.w})$ resulted in the restoration of the histological architecture of the islets of Langerhans in diabetic mice [76]. The possible action mechanism by which $A$. unedo exerts its hypoglycemic effect may be related to the pancreatic secretion of insulin from the existing beta cells or by its release from the bound form [77].

The effects of the root bark aqueous extract of $A$. unedo on intestinal glucose absorption was studied by Mrabti and coworkers in vitro and in vivo. Results showed that the tested extract $(10 \mu \mathrm{g} / \mathrm{mL}$ to $1 \mathrm{mg} / \mathrm{mL})$ inhibited dose-dependent sodium-dependent glucose transport across isolated mouse jejunum with an $\mathrm{IC}_{50}$ value close to $216 \mu \mathrm{g} / \mathrm{mL}$. In addition, the $A$. unedo extract $(2 \mathrm{~g} / \mathrm{kg} /$ day $)$ improved oral glucose tolerance and reduced body weight after chronic oral administration during 4 weeks in rats [78]. These results support the traditional use of $A$. unedo in the treatment of diabetes.

In another study, Mrabti and colleagues isolated catechin from $A$. unedo roots and evaluated its antidiabetic activity using the $\alpha$-glucosidase test. Results showed that the isolated compound exerted antidiabetic activity through inhibition of $\alpha$-glucosidase enzyme activity with an $\mathrm{IC}_{50}$ value of 
TABle 3: Pharmacological activities of A. unedo $L$.

\begin{tabular}{|c|c|c|c|c|c|}
\hline $\begin{array}{l}\text { Pharmacological } \\
\text { effect }\end{array}$ & Plant part & Extract/fraction & Model applied & Effect/mechanism(s) of action & References \\
\hline \multirow{10}{*}{ Antidiabetic activity } & & & OGTT & Antihyperglycemic effect & \\
\hline & Roots & Water & IVGTT & $\begin{array}{c}\text { Inhibition of jejunal glucose } \\
\text { absorption }\end{array}$ & {$[41]$} \\
\hline & & & OGTT & $\begin{array}{l}\text { Hypoglycemic effect in } \mathrm{n} \text {-stz } \\
\text { induced-diabetic rats (in vivo) }\end{array}$ & \\
\hline & Roots & Water & $\begin{array}{l}\mathrm{n} \text {-stz-induced diabetic } \\
\text { rats (in vivo) }\end{array}$ & $\begin{array}{l}\text { Potentiation of the insulin } \\
\text { activity }\end{array}$ & {$[46]$} \\
\hline & & & & $\begin{array}{l}\text { Improved glucose peripheral } \\
\text { consumption }\end{array}$ & \\
\hline & & & & Antidiabetic effect through & \\
\hline & Roots & Catechin & $\alpha$-glucosidase assay & $\begin{array}{l}\text { inhibition of } \alpha \text {-glucosidase } \\
\text { enzyme }\end{array}$ & {$[50]$} \\
\hline & Roots & Water & $\begin{array}{c}\alpha \text {-glucosidase and } \\
\alpha \text {-amylase assays } \\
\text { STZ-NA-induced- } \\
\text { diabetic mice (in vivo) }\end{array}$ & $\begin{array}{c}\text { Inhibition of } \alpha \text {-glucosidase } \\
\text { and } \alpha \text {-amylase } \\
\text { Regeneration of pancreatic } \\
\quad \beta \text {-cells }\end{array}$ & {$[76]$} \\
\hline & & & OGTT & Inhibition of SGLT & \\
\hline & Roots bark & Water & $\begin{array}{l}\text { Short-circuit current } \\
\text { technique (in vitro) }\end{array}$ & $\begin{array}{l}\text { Improved oral glucose } \\
\text { tolerance }\end{array}$ & {$[78]$} \\
\hline \multirow{5}{*}{$\begin{array}{l}\text { Antihypertensive } \\
\text { and vasorelaxant } \\
\text { activity }\end{array}$} & $\begin{array}{l}\text { Roots and } \\
\text { leaves }\end{array}$ & Water & $\begin{array}{l}\text { In vivo determination of } \\
\text { both blood pressure and } \\
\text { baroreflex sensitivity. } \\
\text { Ex vivo analysis of } \\
\text { vascular reactivity. }\end{array}$ & $\begin{array}{l}\text { Reduces the development of } \\
\text { increased SBP } \\
\text { Ameliorates vascular } \\
\text { reactivity and baroreflex } \\
\text { sensitivity } \\
\text { Normalizes renal function } \\
\text { Prevents the myocardial } \\
\text { hypertrophy (roots extract) }\end{array}$ & {$[42]$} \\
\hline & Leaves & $\begin{array}{l}\text { Aqueous extract soxhlet } \\
\text { extraction: Hexane, } \\
\text { dichloromethane, ethyl } \\
\text { acetate, methanol and water }\end{array}$ & $\begin{array}{l}\text { In vitro study of } \\
\text { vasorelaxant effect }\end{array}$ & $\begin{array}{l}\text { Endothelium-dependent } \\
\text { vasorelaxant activity mediated } \\
\text { by NO. This effect is due to the } \\
\text { presence of condensed } \\
\text { tannins and catechin gallate. }\end{array}$ & {$[47]$} \\
\hline & Roots & Water extract & $\begin{array}{l}\text { In vitro study of } \\
\text { vasodilator effect and } \\
\text { mechanisms of action }\end{array}$ & $\begin{array}{l}\text { Endothelium-dependent } \\
\text { relaxation of aorta mainly } \\
\text { mediated by a stimulation of } \\
\text { endothelial NO synthase }\end{array}$ & [43] \\
\hline & \multirow[b]{2}{*}{ Roots } & \multirow[b]{2}{*}{ Water } & $\begin{array}{l}\text { In vivo study of } \\
\text { hypertension }\end{array}$ & $\begin{array}{c}\text { Delayed the development of } \\
\text { hypertension }\end{array}$ & [49] \\
\hline & & & Measurement of diuresis & $\begin{array}{c}\text { Attenuated the pressor } \\
\text { responses to phenylephrine } \\
\text { and angiotensin I diuretic } \\
\text { effect }\end{array}$ & \\
\hline
\end{tabular}


TABle 3: Continued.

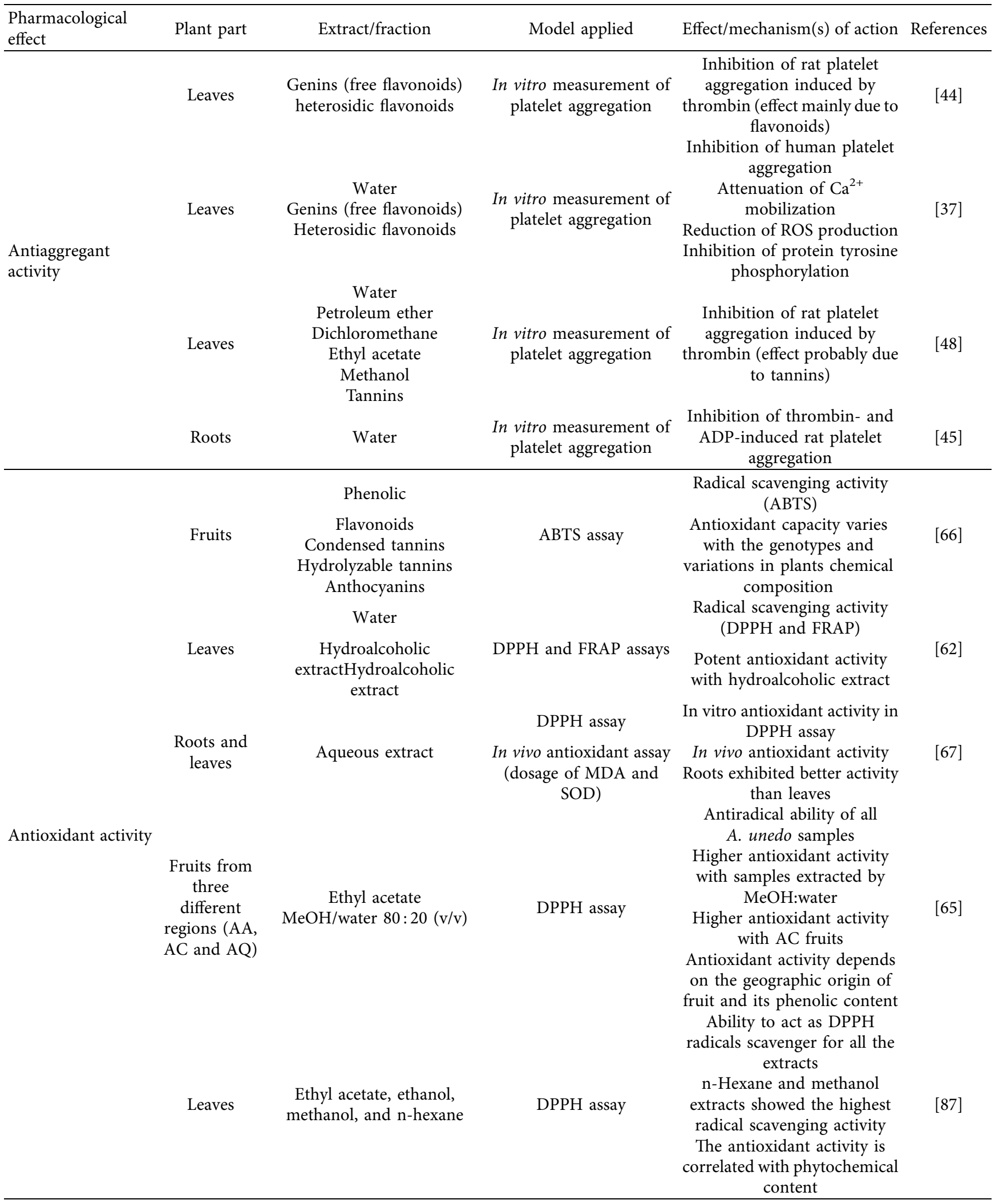


TABLE 3: Continued.

\begin{tabular}{|c|c|c|c|c|c|}
\hline $\begin{array}{l}\text { Pharmacological } \\
\text { effect }\end{array}$ & Plant part & Extract/fraction & Model applied & Effect/mechanism(s) of action & References \\
\hline \multirow{3}{*}{$\begin{array}{l}\text { Antibacterial and } \\
\text { antiparasitic activity }\end{array}$} & Leaves & $\begin{array}{l}\text { Ethyl acetate, ethanol, } \\
\text { methanol, and } n \text {-hexane. }\end{array}$ & $\begin{array}{l}\text { Determination of MIC } \\
\text { by the dilution agar } \\
\text { method. }\end{array}$ & $\begin{array}{c}\text { Antibacterial activity against } \\
\text { gram-negative (Escherichia } \\
\text { coli, Pseudomonas aeruginosa) } \\
\text { and gram-positive } \\
\text { (Staphylococcus aureus, } \\
\text { Listeria monocytogenes) } \\
\text { bacteria }\end{array}$ & {$[87]$} \\
\hline & Leaves & Ethanol & $\begin{array}{l}\text { Determination of growth } \\
\text { inhibition values by } \\
\text { paper disc }\end{array}$ & $\begin{array}{l}\text { Antimycobacterial activity } \\
\text { against Mycobacterium bovis, } \\
\text { Mycobacterium smegmatis } \\
\text { and Mycobacterium aurum }\end{array}$ & {$[90]$} \\
\hline & Leaves & $\begin{array}{l}n \text {-hexane, methanol, and } \\
\text { ethanol }\end{array}$ & MTT assay & $\begin{array}{c}\text { Antileishmanial activity using } \\
\text { Leishmania major, } \\
\text { Leishmania tropica, and } \\
\text { Leishmania infantum }\end{array}$ & {$[93]$} \\
\hline \multirow{3}{*}{$\begin{array}{l}\text { Anticancer and } \\
\text { cytotoxic activity }\end{array}$} & Leaves & $\begin{array}{l}n \text {-hexane, methanol, and } \\
\text { ethanol }\end{array}$ & $\begin{array}{c}\text { MTT assay } \\
\text { Cancerous cell lines: } \\
\text { L20B, RD and vero } \\
\text { Normal cells: PBMC }\end{array}$ & $\begin{array}{l}\text { Cytotoxic effects against } \\
\text { L20 B, RD and vero cell lines } \\
\text { with } A \text {. unedo } n \text {-hexane } \\
\text { extract }\end{array}$ & {$[94]$} \\
\hline & Leaves & Water & $\begin{array}{l}\text { Cell viability evaluated } \\
\text { using calcein and trypan } \\
\text { blue. }\end{array}$ & $\begin{array}{l}\text { No toxic effect was observed } \\
\text { in human platelets cell } \\
\text { viability with a concentration } \\
\text { of } 1.5 \mathrm{mg} / \mathrm{mL}\end{array}$ & {$[37]$} \\
\hline & Leaves & Ethanol & Neutral red uptake assay & $\begin{array}{c}\text { No toxic effect was observed } \\
\text { in peritoneal macrophages } \\
\text { with a concentration of } \\
6.02 \pm 0.76 \mathrm{mg} / \mathrm{mL}\end{array}$ & {$[90]$} \\
\hline \multirow{3}{*}{ Antilithiasic activity } & Leaves & Hydroalcoholic extract & $\begin{array}{l}\text { Measurement of } \\
\text { litholytic activity using a } \\
\text { model structure } \\
\text { resembling the urinary } \\
\text { circuit }\end{array}$ & $\begin{array}{l}\text { Litholytic activity against } \\
\text { calcium oxalate stones } \\
\text { Higher litholytic activity with } \\
\text { aqueous extract }\end{array}$ & {$[62]$} \\
\hline & Leaves & $\begin{array}{c}\text { Water } \\
\text { Hydroalcoholic extract }\end{array}$ & $\begin{array}{l}\text { In vitro measurement of } \\
\text { the crystal formation by } \\
\text { using a UV-Visible } \\
\text { spectrophotometer } \\
\text { Microscopic observation } \\
\text { of the crystals }\end{array}$ & $\begin{array}{c}\text { Inhibitory activity against } \\
\text { calcium oxalate crystallization } \\
\text { Higher litholytic activity with } \\
\text { aqueous extract } \\
\text { This effect is due to the } \\
\text { presence of polar compounds } \\
\text { in the plant extracts such as } \\
\text { polyphenols }\end{array}$ & {$[63]$} \\
\hline & $\begin{array}{l}\text { Fruits } \\
\text { (seeds) }\end{array}$ & Water & $\begin{array}{l}\text { Polarizing optical } \\
\text { microscope (PLM) }\end{array}$ & $\begin{array}{c}\text { Inhibition of the } \\
\text { crystallization of calcium } \\
\text { oxalate }\end{array}$ & {$[100]$} \\
\hline
\end{tabular}

OGTT, oral glucose tolerance test; n-stz, neonatal streptozotocin; IVGTT, intravenous glucose tolerance test; STZ-NA, streptozotocin-nicotinamide; SGLT, sodium-dependent glucose transporter; SBP, systolic blood pressure; NO, nitric oxide; Ca2+, calcium; ROS, reactive oxygen species; ABTS, 2,20-azinobis-(3ethylbenzothiazoline-6-sulfonic acid); DPPH, 1,1-diphenyl-2-picrylhydrazyl; FRAP, ferric reducing/antioxidant power; ADP, adenosine diphosphate; SOD, superoxide dismutase; MDA, malondialdehyde; AA, achakar; AQ, qsar Kbir; AC, chaoun-Qalaa; MIC, minimal inhibitory concentration; MTT, (3-(4,5dimethylthiazol-2-yl)-2,5-diphenyl tetrazolium bromide).

$87.55 \pm 2.23 \mu \mathrm{g} / \mathrm{mL}[50]$. The inhibitory potential of catechin was greater than that of the positive control acarbose $\left(\mathrm{IC}_{50}=199.53 \pm 1.12 \mu \mathrm{g} / \mathrm{mL}\right)$. The antidiabetic activity for root extract of $A$. unedo is very well established by various researchers. Therefore, there is need to explore the potential of $A$. unedo leaves to treat diabetes. However, there is no adequate studies on the effect of $A$. unedo extracts with respect to molecular aspects.
7.2. Antihypertensive and Vasorelaxant Activity. Hypertension is a major risk factor for CVD, such as coronary heart disease and stroke, the two leading causes of death among adults worldwide [79]. In addition, current antihypertensive agents have limited effectiveness and various side effects. Recently, various studies have been focused to find new drugs from medicinal plants with antihypertensive properties. 


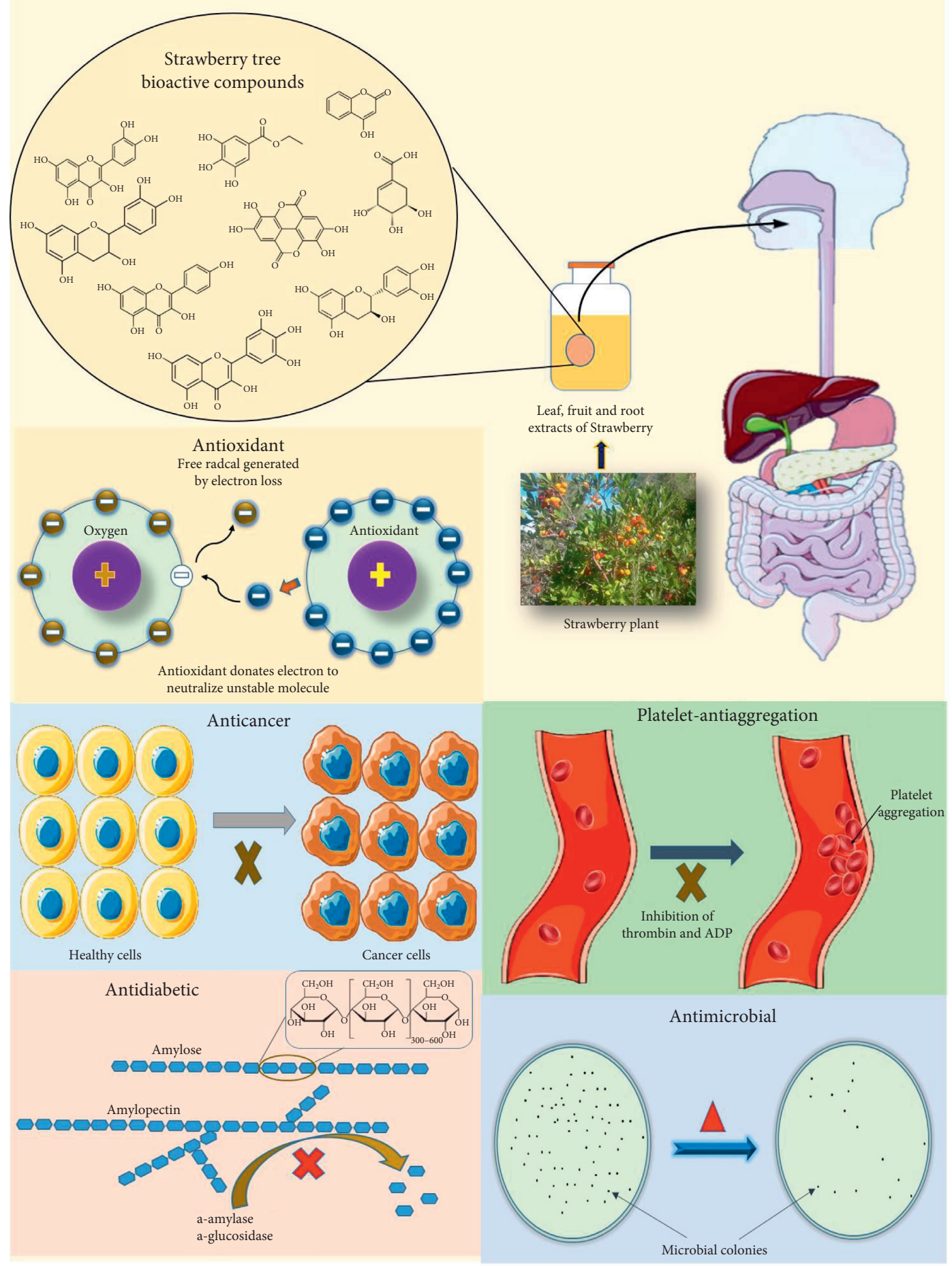

Figure 5: Representation of some pharmacological activities of Arbutus unedo L.

A. unedo has been tested for antihypertensive activity. Afkir et al. reported that the simultaneous oral treatment of rats with L-NG-nitroarginine methyl ester (L-NAME) and A. unedo leaf or root aqueous extract $(250 \mathrm{mg} / \mathrm{Kg} /$ day $)$ for 4 weeks inhibited hypertension development and reduced ventricular hypertrophy (root extract). Furthermore, the extracts normalized renal function, improved vascular reactivity, and baroreflex sensitivity in rats [42].
In another pre-clinical study, it has been reported that the chronic treatment of spontaneously hypertensive rats (SHR) with $A$. unedo root aqueous extracts $(5,50$ and $250 \mathrm{mg} / \mathrm{kg} / 24 \mathrm{~h}$ ) delayed the development of hypertension but did not change the final level of blood pressure and heart rate. A diuretic effect was observed in the group receiving the highest dose $(250 \mathrm{mg} / \mathrm{kg} / 24 \mathrm{~h})$ of $A$. unedo [49]. 
The vascular activity of $A$. unedo roots was also examined in vitro using isolated rat aorta. It has been found that the root aqueous extract $(0.25 \mathrm{mg} / \mathrm{mL})$ induced an endotheliumdependent vasodilation of the isolated rat aorta, and this effect was mainly attributed to the activation of the endothelial nitric oxide synthase (NOS) [43].

In another in vitro study, Legssyer and colleagues examined the vascular effect of aqueous extract from A. unedo leaves on the isolated rat aorta. Results showed that the Arbutus leaf extract $(0.01 \mathrm{~g} / \mathrm{L})$ produced a strong endothelium-dependent vasorelaxant activity. A chromatographic fractionation of the methanolic extract of A. unedo leaves showed that this vasorelaxant activity was probably assigned to polyphenolic compounds, such as tannins and catechin gallate [47]. It was suggested that these findings may account for the antihypertensive property of $A$. unedo reported in folk medicine. Furthermore, studies are required to unravel the molecular mechanism of action of phytochemicals present in A. unedo extracts.

7.3. Antiaggregant Effect. Blood platelets play a crucial role in the primary hemostasis through the formation of a platelet clot. However, platelet hyperactivity is mainly involved in thrombosis and atherosclerosis [37, 80, 81]. Furthermore, the use of anti-platelet agents is often associated with various adverse effects including bleeding problem and gastric problems [82]. In this context, the development of anti-platelet drugs of natural origin is of great interest [2].

In a study, the platelet antiaggregant effect of $A$. unedo was investigated in vitro by a group of researchers using different extract preparations. In a screening study, it was demonstrated that $A$. unedo root extract from Tazekka Mountain inhibited in vitro platelet aggregation induced by thrombin or ADP in a dose-dependent manner [45]. In another investigation, it was reported that the leaf aqueous extract of the plant inhibited thrombin-induced rat platelet aggregation in vitro with an $\mathrm{IC}_{50}$ value of $1.8 \mathrm{~g} / \mathrm{l}$. Successive extraction of $A$. unedo leaves with solvents of increasing polarity (petroleum ether, dichloromethane, ethyl acetate, and methanol) revealed that ethyl acetate and the methanolic extracts were most active against platelet aggregation with $\mathrm{IC}_{50}$ values of $0.6 \pm 0.05$ and $0.7 \pm 0.08 \mathrm{~g} / \mathrm{L}$, respectively [48]. In order to verify if the tannins were implicated in the obtained antiaggregant effects, these compounds were isolated from the methanolic extract, and their anti-platelet effect was evaluated in vitro. The obtained results indicated that tannins precipitated by caffeine induced an important antiaggregant effect, whereas the adsorption of these compounds by skin powder in the methanol extract reduced significantly its activity. Thus, the antiplatelet aggregation effect of the $A$. unedo leaf extract was mainly attributed to condensed tannins [48].

In another study, researchers examined the anti-platelet effect of flavonoids from A. unedo leaves in vitro. It has been found that genins (free flavonoids) hetrosidic flavonoids reduced significantly thrombin-induced platelet aggregation with IC50 values of $0.22 \pm 0.03$ and $0.36 \pm 0.05 \mathrm{mg} / \mathrm{ml}$, respectively. In addition, at $1 \mathrm{mg} / \mathrm{ml}$, these compounds reduced significantly the initial rate of platelet aggregation by $97.8 \pm 0.74 \%$ and $90.8 \pm 1.55 \%$ for genins and heterosidic flavonoids, respectively [44]. Thus, these findings clearly demonstrate that the anti-platelet effect of $A$. unedo is mainly attributed to flavonoids.

In addition to our work on rat platelets, we have investigated the effects of flavonoids from $A$. unedo leaves on human platelets. It has been found that the aqueous extract and flavonoids from $A$. unedo leaves exerted anti-platelet effects in human platelets [37]. Furthermore, it was demonstrated that at $0.05 \mathrm{mg} / \mathrm{mL}$, the tested compounds reduced thrombin-induced endogenous ROS production, as well as $\mathrm{Ca}^{2+}$ mobilization and protein tyrosine phosphorylation, two processes that have been revealed to be regulated by the redox potential in platelets $[83,84]$. These findings are in agreement with the antiaggregant effect of $A$. unedo observed in rat platelets $[45,48]$, although, it should be noted that human platelets seems to be more sensitive to the extracts than rat platelets. It was concluded that $A$. unedo extracts exhibited anti-platelet activity by a mechanism implying the reduction of $\mathrm{Ca}^{2+}$ mobilization, ROS production, and protein tyrosine phosphorylation, which might support the traditional use of this plant in the treatment and/ or prevention of CVD. However, further studies to understand its molecular mechanism and in-depth in vivo investigations may help to include $A$. unedo as an alternative to modern medicine.

7.4. Antioxidant Activity. Oxidative stress has been mainly implied in the development of chronic and degenerative diseases such as cancer, diabetes, and cardiovascular and neurological diseases [85]. Increased consumption of plantbased foods (fruits, vegetables, and nuts) has been reported to reduce and prevent damage caused by free radicals [86].

Numerous studies have evaluated the antioxidant activity of A. unedo in vitro and in vivo. Different compounds were isolated from the plant and were evaluated for their antioxidant potential. Recently, Zitouni and coworkers [64] evaluated in vitro the antioxidant properties of $A$. unedo fruits from different areas of Morocco using three antioxidant essays (1,1-diphenyl-2-picrylhydrazyl (DPPH), 2,2azinobis-(3-ethylbenzothiazoline-6-sulfonic acid) (ABTS), and $\beta$-Carotene bleaching). Results revealed significant differences among sampled fruits. The average radical scavenging capacities were 3.33-21.08, 2.25-19.58, and 1.08-13 mg Ascorbic Acid Equivalent (AAE)/g d.w) for the $\mathrm{DPPH}, \mathrm{ABTS}$, and $\beta$-carotene bleaching assays, respectively. The authors suggested that the difference in results might be due to difference in varieties and/or growing region of the A. unedo samples.

In another recent study, Zitouni and colleagues assessed the antioxidant activity of phenolic, flavonoids, condensed tannins, hydrolyzable tannins and anthocyanins from twelve A. unedo fruits genotypes using ABTS. Significant variations were observed in the antioxidant activity among the studied extracts. The $\mathrm{IC}_{50}$ value (ABTS) of the tested compounds 
varied from 1.75 to $19.58 \mathrm{mg} \mathrm{AAE} / \mathrm{g} \mathrm{d.w}$ [66]. It is noticeable that the antioxidant activities of the tested compounds depend on the region and diversity of geographical environments.

Kachkoul and coworkers analyzed the antioxidant activity of aqueous and hydroalcoholic extracts from $A$. unedo leaves using DPPH and the ferric reducing/antioxidant power (FRAP) assays. It has been found that the hydroalcoholic extract exerted higher antioxidant capacity than the aqueous extract with $\mathrm{IC}_{50}$ values of $76.14 \pm 0.91 \mu \mathrm{g} / \mathrm{mL}$ for hydroalcoholic extract versus $202.64 \pm 5.77 \mu \mathrm{g} / \mathrm{mL}$ for aqueous extract using the DPPH assay, and $53.77 \pm 0.81 \mu \mathrm{g} /$ $\mathrm{mL}$ for hydroalcoholic extract versus $236.86 \pm 31.90 \mu \mathrm{g} / \mathrm{mL}$ for aqueous extract using the FRAP test [62].

The antioxidant activity of $A$. unedo roots and leaves aqueous extracts was determined by Mrabti et al. in vitro and in vivo. The in vitro antioxidant activity was determined using the DPPH assay, while the in vivo activity was analyzed by dosage of malondialdehyde (MDA) and superoxide dismutase (SOD) in diabetic mice. The $\mathrm{IC}_{50}$ values for the in vitro antioxidant activity of the aqueous extract was 4.52 and $7.24 \mu \mathrm{g} / \mathrm{mL}$ in roots and leaves, respectively [67]. In addition, there was no significant difference between $A$. unedo and metformin group (positive control) in all of the in vivo examined parameters (MDA and SOD) in liver and kidney of diabetic mice [67]. The high antioxidant potential of the roots is compatible with their higher content in tannins, anthraquinones, terpenoids, and flavonoids. These results suggest that $A$. unedo may strengthen the enzymatic antioxidant system and reduce tissue damage due to oxidative stress.

In another study, Bouyahya and coauthors assessed the antioxidant activity of methanolic, ethanolic, ethyl acetate and $\mathrm{n}$-hexanic extract from $A$. unedo leaves using DPPH assay. It has been found that the plant extracts showed an antioxidant effect against DPPH radicals. In addition, n-hexane and methanol extracts were found to exert the highest radical scavenging activity with $\mathrm{IC}_{50}$ values of $73.73 \mu \mathrm{g} / \mathrm{mL}$ and $95.25 \mu \mathrm{g} / \mathrm{mL}$, respectively [87]. The differences of the obtained results could be related to the type of solvents and the nature of phytochemical content of each extract.

In a recent study, El Cadi et al. determined the antioxidant capacity of $A$. unedo fruits from three locations of northern Morocco (Achakar, Qsar Kbir and Chaoun-Qalaa) using the DPPH assay. Results showed that all the samples have antioxidant activity (EC50 values between $1.37 \pm 0.2$ and $17.82 \pm 0.12 \mathrm{mg} / \mathrm{mL}(\mathrm{w} / \mathrm{v})$ ). Higher antioxidant capacity was observed with samples extracted by $\mathrm{MeOH}$ :water. In addition, Chaoun-Qalaa fruits were found to exhibit the highest antioxidant activity, which is compatible with their higher total polyphenol and flavonoid content [65]. The authors concluded that $A$. unedo fruits contain various phytochemicals with high antioxidant capacity, and could be, therefore, used in pharmacological and nutritional research. The antioxidant potential of $A$. unedo extracts has been justified by several in vitro and in vivo investigations, still there is enough scope to study the effect of phytochemicals present in A. unedo on gene expression levels.
Additionally, these investigations mainly used the whole crude extracts of $A$. unedo root and leaves instead of the bioactive compounds.

7.5. Antibacterial and Antiparasitic Activity. Antimicrobial agents play a major role against infectious diseases. However, the consumption of antibiotics can lead over time to the development of a more resistant bacteria [88]. Antimicrobial resistance makes antibiotics less effective, and infections become difficult to be treated. Thus, the need to find new and efficient antimicrobial agents is of great interest. In this sense, various medicinal herbs have been used due to their antimicrobial properties [89].

Bouyahya and coworkers determined the antimicrobial activity of methanolic, $n$-hexanic, ethyl acetate, and ethanolic extract from $A$. unedo leaves against Escherichia coli K12 MBLA, Staphylococus aureus CECT 976, Listeria monocytogenes Serovar 4b CECT 4032, and Pseudomonas aeruginosa $\mathrm{IH}$ using the agar well diffusion assay. A significant difference in activities was observed against the studied bacterial strains. The highest activity was obtained with the $n$-hexanic extract, particularly against $S$. aureus and L. monocytogenes (zones of inhibition varied from $34.42 \pm 0.26 \mathrm{~mm}$ to $40 \pm 0.19 \mathrm{~mm}$ ) [87]. The inhibition was related to the presence of phenolic and flavonoid compounds.

In another study, the extra- and intracellular antimycobacterial activities of aqueous and ethanol extracts from $A$. unedo leaves were studied against the growth of three mycobacteria (Mycobacterium bovis, Mycobacterium smegmatis, and Mycobacterium aurum). Results showed that the tested extracts exhibited extracellular antimycobacterial activity against the growth of three mycobacteria. The minimum inhibitory concentration (MIC) of the ethanolic extract was $5.59 \pm 0.69 \mathrm{mg} / \mathrm{ml}$ for Mycobacterium aurum A+ and $6.02 \pm 0.76 \mathrm{mg} / \mathrm{ml}$ for Mycobacterium smegmatis MC2 and Mycobacterium bovis PPI. Moreover, ethanol extract used at $6.02 \pm 0.76 \mathrm{mg} / \mathrm{ml}$ showed potent intracellular antimycobacterial activity against $M$. smegmatis MC2 located within the rat peritoneal macrophages [90]. The antimycobacterial activity of the plant could be assigned to a number of phytochemicals, such as phenolic compounds.

Leishmaniasis is a parasitic disease caused by Leishmania parasites, which are transmitted by phlebotomy insects. It constitutes a serious health problem worldwide, especially in Africa [91, 92]. Therefore, the search for antileishmanial drugs with no side effects is of great interest. In this sense, the antileishmanial activity of methanolic, $n$-hexanic, and ethanolic extract of four medicinal plants including $A$. unedo was examined by Bouyahya et al. against Leishmania major, Leishmania tropica, and Leishmania infantum using the MTT (3-(4.5-dimethylthiazol- 2yl)-2.5-diphenyltetrazolium bromide) assay. Results indicated that the $n$-hexanic extract from $A$. unedo leaves exhibited profound and highly significant inhibitory effect against $L$. infantum $\left(\mathrm{IC}_{50}=64.05 \pm 1.44 \mu / \mathrm{mL}\right)$ and L. tropica $\left(\mathrm{IC}_{50}=79.57 \pm 2.66 \mu \mathrm{g} / \mathrm{mL}\right)$ [93]. The authors suggested that A. unedo could constitute a potential source for 
antileishmanial agents. However, further research is needed to identify the bioactive compounds that are responsible for the antileishmanial activity and to determine their modes of action.

7.6. Anticancer and Cytotoxic Activity. The anticancer activity of methanolic, $n$-hexanic, and ethanolic extract from five medicinal plants including $A$. unedo was investigated in vitro against different cancer cell lines (L20B, RD and Vero) using the MTT assay. The pharmacological selectivity index (PSI) was calculated using PBMC as the normal cell line. It has been found that the $\mathrm{n}$-hexanic extract of $A$. unedo leaves significantly inhibited the proliferation of $\mathrm{RD}$ $\left(\mathrm{IC}_{50}=27.83 \pm 1.20 \mu \mathrm{g} / \mathrm{mL} ; \quad\right.$ PSI $\left.=0.69\right), \quad$ L20 B $\left(\mathrm{IC}_{50}=25.32 \pm 1.26 \mu \mathrm{g} / \mathrm{mL} ; \mathrm{PSI}=0.76\right)$, and Vero cell lines $\left(\mathrm{IC}_{50}=18.37 \pm 1.23 \mu \mathrm{g} / \mathrm{ml} ; \quad \mathrm{PSI}=1.05\right) \quad$ [94]. As there are limited studies on the anticancer activity of the $A$. unedo extract, furthermore, in vitro as well as in vivo investigations are required to consolidate the role of $A$. unedo extract as a potential anticancerous drug. In addition, most of researchers focused on the whole crude extracts of $A$. unedo instead of the bioactive components with molecular mechanisms mostly unclear.

7.7. Antilithiasis Activity. Urolithiasis is a pathological problem that involves the formation of crystalline aggregates called "urinary stones" in the kidneys or in the urinary tract. The etiology of this disorder is related to a variety of metabolic and environmental disturbances [95]. Until now, there has been no satisfactory treatment for urolithiasis. Furthermore, medical management of urolithiasis can lead to side effects, which are sometimes very serious [96]. Thus, several medicinal plants have been used for the treatment and/or prevention of urolithiasis [97, 98].

Little information was recorded with the antilithiasic activity of $A$. unedo. A study by Kachkoul and coworkers assessed the effects of $A$. unedo leaf extracts (aqueous and hydroalcoholic extracts) on calcium oxalate crystallization in vitro. It has been found that the aqueous extract was more effective in the dissolution of calcium oxalate stones than the hydroalcoholic extract with dissolution values of $31.05 \%$ and $14.55 \%$, respectively [62]. Another in vitro study on calcium oxalate crystallization has been performed with aqueous and hydroalcoholic extracts from $A$. unedo leaves using UVvisible spectrophotometric method. Results showed a higher potency of the plant aqueous extract compared to the hydroalcoholic extract against crystallization or nucleation at percentages of $69.41 \pm 0.24$ or $19.76 \pm 0.27 \%$ and at $93.92 \pm 2.61$ and $45.16 \pm 3.06 \%$ against the aggregation for both the aqueous and the hydroalcoholic extract, respectively [63]. This antilithiasic activity could be attributed to the high level of phenolic components contained in the leaves [63], which are known for their anticrystallizing property according to studies of both human urine as well as on animal models [99]. The authors concluded that $A$. unedo is a promising and effective remedy against "urinary stones".

In a recent study, Baddade and colleagues investigated the antilithiasic activity of $A$. unedo fruits in vitro. Fruit samples were collected from six zones from the Beni Mellal-Khenifra region, and the antilithiasic activity was evaluated against the aggregation of calcium oxalate. Results showed that the fruit seed aqueous extract $(3 \mathrm{mg} / \mathrm{ml})$ inhibited the crystallization of calcium oxalate in vitro. At $10 \mathrm{mg} / \mathrm{ml}$, the extract showed significant dissociation of the aggregates [100]. The authors suggested that $A$. unedo extracts seem to be promising against the crystallization of calcium oxalate, especially in the aggregation and nucleation stages.

\section{Toxicological Properties}

According to different toxicity tests, the use of $A$. unedo is devoid of any significant side effects and/or toxicity. Indeed, in an acute toxicity test performed in mice, we have demonstrated that the oral administration of $A$. unedo leaf aqueous extract at a dose up to $1200 \mathrm{mg} / \mathrm{kg}$ caused no mortality and no signs of adverse effects, demonstrating that the $\mathrm{LD}_{50}$ value of the $A$. unedo aqueous extract was higher than $1200 \mathrm{mg} / \mathrm{kg}$ b.w in oral administration in mice [44]. In another acute toxicity test realized in mice, it has been reported that the $A$. unedo root aqueous extract exhibited $\mathrm{LD}_{50}$ higher than $2000 \mathrm{mg} / \mathrm{kg}$ b.w with no adverse effect of this dose shown after single oral administration in mice [76]. Furthermore, in a study to analyze the acute toxicity of A. unedo and to evaluate its safety, an aqueous extract from A. unedo roots was intraperitoneally administrated in mice. The results did not show visible signs of toxicity or adverse effects even at a dose of $6 \mathrm{~g} / \mathrm{kg}$ b.w [41].

The cytotoxicity of rat peritoneal macrophages treated with the ethanolic extract of $A$. unedo leaves was measured by the neutral red uptake assay. Results showed that rat peritoneal macrophages treated with the extract $(6.02 \pm 0.76 \mathrm{mg} / \mathrm{ml})$ were able to uptake the red neutral dye after 3 days of incubation. It is concluded that the extract used at $6.02 \pm 0.76 \mathrm{mg} / \mathrm{ml}$ had no cytotoxic effect [90]. In a previous study, we have examined the cytotoxic effect of A. unedo on platelet cell viability using calcein and trypan blue. Results showed that the incubation of human platelets with $A$. unedo leaf aqueous extracts $(1.5 \mathrm{mg} / \mathrm{ml})$ did not affect their viability [37].

\section{Discussion}

In the current review, we report the traditional medicinal uses and phytochemical and pharmacological properties of $A$. unedo from Morocco. Various A. unedo extract preparations have been broadly used in folk medicine for the management of several ailments. Different parts of the plant are used in the prevention and treatment of several complications, especially microbial infection, diabetes, hypertension, and gastrointestinal and renal diseases. In contrast, limited studies have been devoted to the plant fruits, although they represent an abundant source of phytochemicals with potent antioxidant capacity. Different traditional uses have been confirmed by pharmacological activities of the plant extracts and its identified compounds using different animal models in vitro and in vivo. Among the bioactive compounds, flavonoids and tannins are the most important, being responsible for most of the 
pharmacological activities reported, namely, antioxidant, antiaggregant, antidiabetic, antihypertensive, antimicrobial, anticancer, or antidiarrheal activities. These activities generally agree with traditional knowledge and folk medicine.

The studied $A$. unedo extracts have been shown to be a rich source of epicatechin, catechin, catechin gallate, flavonoids, anthocyanins and tannins, and phytochemicals with wellrecognized antioxidant capacity. The antioxidant properties of A. unedo extracts have been evidenced in different in vitro systems and in vivo studies in rats, mice, and cell culture systems. The antihypertensive, anti-platelet, anticancer, and antidiabetic properties of the plant are all believed to be related to its antioxidant activity, although no direct associations have been made.

Various studies involving catechin, epicatechin, tannins, anthocyanins, and flavonoid-rich extracts from other plants have demonstrated antiaggregant [101-104], antidiabetic [105], anticancer [106], and vasodilation properties [107]. Therefore, it is not surprising that various $A$. unedo extracts exhibit these properties due to the presence of catechins, anthocyanins, and flavonoids. Significant variations were observed in phytochemical composition among investigated $A$. unedo extracts, which are mainly due to genetic variability and environmental factors, such as bioclimatic or geographical origin $[39,54,55,64]$. Furthermore, it was revealed that the biological properties of $A$. unedo depend on the extraction method, the nature of phytochemicals, and their levels in the plant extracts.

The retrieved studies were insufficient to substantiate all the traditional medicinal claims of the plant. Moreover, most of the studies that highlighted the beneficial properties of $A$. unedo on health were in vitro and in vivo investigations on animal models as well as several cell lines, which represent one of the limitations in this review. Thus, more clinical studies are necessary to validate the traditional uses and pharmacological activities of the selected plant.

In addition to details regarding the traditional use of A. unedo, this review also focuses on the nutritional characteristics of the plant and its potential uses for other industries, such as food, cosmetics, or pharmaceutical ones, especially the fruit, which constitutes an important source of compounds with beneficial health properties such as minerals, vitamins, fiber, flavonoids, and tannins.

Different parts of the plant have been used for a long time without any toxicity or side effects. In addition, $A$. unedo fruits have been consumed for many years in folk medicine due to its medicinal properties and nutritional value with no known toxicity. Furthermore, toxicity tests carried out on animals or in vitro did not demonstrate any toxic effects on the plant. However, we note the absence of long-term studies either on animals or on humans that could address its long-term safety. Thus, unlike pharmaceutical drugs, A. unedo not only has no side effects, but has various medicinal properties against several diseases.

\section{Conclusion}

Numerous studies have reported that $A$. unedo is an important source of catechins, tannins, anthocyanins, as well as flavonoids with potent antioxidant capacity. The antioxidant properties of the plant have been well demonstrated through both in vitro and in vivo investigations. The antioxidant activity of the plant seems to be responsible for the antidiabetic, anticancer, antiaggregant, and antihypertensive activities that have been demonstrated. However, the majority of the phytochemical investigations was limited to screening studies rather than the isolation of bioactive constituents. In addition, several researchers focused on the whole crude extracts of $A$. unedo instead of the bioactive components, with molecular mechanisms mostly unclear. Additionally, no human clinical studies have been reported. In light of this, relevant goals for future research are the identification of bioactive molecules from A. unedo using bioguided isolation assays and finding evidence for their beneficial health effects through preclinical and clinical studies. The physical properties of the equipment used in the transport, storage, harvesting, and processing of $A$. unedo fruits must also be investigated.

\section{Abbreviations \\ WHO: World health organization \\ DM: $\quad$ Diabetes mellitus \\ A. unedo: Arbutus unedo \\ B.W: $\quad$ Body weight \\ $\mathrm{Ca}^{2+}$ : Calcium \\ $\mathrm{IC}_{50}$ : Median inhibitory concentration \\ D.W: Dry weight \\ ROS: $\quad$ Reactive oxygen species \\ CVD: Cardiovascular diseases.}

\section{Data Availability}

The data supporting this review were taken from previously reported studies and datasets, which have been cited. The processed data are available from the corresponding author upon request.

\section{Conflicts of Interest}

The authors declare no potential conflicts of interest.

\section{Acknowledgments}

The authors would like to thank Prof. Rachid Touzani from the Department of Chemistry, Faculty of Sciences, Oujda, for his valuable help in drawing the molecule of catechin. No financial support was received for this work.

\section{References}

[1] T. B. Ng, F. Liu, and Z. T. Wang, "Antioxidative activity of natural products from plants," Life Sciences, vol. 66, no. 8, pp. 709-723, 2000.

[2] M. El Haouari and J. A. Rosado, "Medicinal plants with antiplatelet activity," Phytotherapy Research, vol. 30, no. 7, pp. 1059-1071, 2016.

[3] M. El Haouari and J. A. Rosado, "Phytochemical, anti-diabetic and cardiovascular properties of urtica dioica L. (urticaceae): a review," Mini Reviews in Medicinal Chemistry, vol. 19, no. 1, pp. 63-71, 2019. 
[4] WHO, WHO Guidelines on Safety Monitoring of Herbal Medicines in Pharmacovigilance Systems, World Health Organization, Geneva, Switzerland, 2004.

[5] WHO, Regulatory Situation of Herbal Medicines: A Worldwide Review, World Health Organization (WHO), Geneva, Switzerland, 1998.

[6] M. G. Hertog, P. M. Sweetnam, A. M. Fehily, P. C. Elwood, and D. Kromhout, "Antioxidant flavonols and ischemic heart disease in a Welsh population of men: the Caerphilly Study," American Journal of Clinical Nutrition, vol. 65, no. 5, pp. 1489-1494, 1997.

[7] F. Turati, M. Rossi, C. Pelucchi, F. Levi, and C. La Vecchia, "Fruit and vegetables and cancer risk: a review of southern European studies," British Journal of Nutrition, vol. 113, no. 2, pp. S102-S110, 2015.

[8] R. Estruch, M. A. Martinez-Gonzalez, and D. Corella, "Effects of a mediterranean-style diet on cardiovascular risk factors," Annals of Internal Medicine, vol. 145, no. 1, pp. 1-11, 2006.

[9] F. Perez-Vizcaino and J. Duarte, "Flavonols and cardiovascular disease," Molecular Aspects of Medicine, vol. 31, no. 6, pp. 478-494, 2010.

[10] L. A. Bazzano, J. He, and L. G. Ogden, "Legume consumption and risk of coronary heart disease in US men and women: NHANES I Epidemiologic Follow-up Study," Archives of Internal Medicine, vol. 161, no. 21, pp. 2573-2578, 2001.

[11] A. A. Izzo, S. Hoon-Kim, R. Radhakrishnan, and E. M. Williamson, "A critical approach to evaluating clinical efficacy, adverse events and drug interactions of herbal remedies," Phytotherapy Research: PT, vol. 30, no. 5, pp. 691-700, 2016.

[12] WHO, Medicine Strategy, World Health Organization, Geneva, Switzerland, 2021.

[13] R. A. Larson, "The antioxidants of higher plants," Phytochemistry, vol. 27, pp. 969-978, 1998.

[14] G. Belakhdar, A. Benjouad, and E. H. Abdennebi, "Determination of some bioactive chemical constituents from Thesium humile Vahl," Journal of Materials and Environmental Science, vol. 6, pp. 2778-2783, 2021.

[15] K. T. Chung, T. Y. Wong, C. I. Wei, Y. W. Huang, and Y. Lin, "Tannins and human health: a review," Critical Reviews in Food Science and Nutrition, vol. 38, no. 6, pp. 421-464, 1998.

[16] G. Celikel, L. Demirsoy, and H. Demirsoy, "The strawberry tree (Arbutus Unedo L.) selection in Turkey," Scientia Horticulturae, vol. 118, pp. 115-119, 2008.

[17] J. Torres, F. Valle, C. Pinto, A. García-Fuentes, C. Salazar, and E. Cano, "Arbutus unedo L. communities in southern Iberian Peninsula mountains," Plant Ecology, vol. 160, no. 2, pp. 207-223, 2002.

[18] T. K. Lim, "Arbutus unedo," in Edible Medicinal and NoinMedicinal Plants, Springer, New York, NY, USA, 1st edition, 2012.

[19] R. Faida, J. Aabdousse, A. Boulli, S. Bouda, and N. Wahid, "Ethnobotanical uses and distribution status of Arbutus unedo in Morocco," Ethnobotany Research and Applications, vol. 18, no. 30, pp. 1-12, 2019.

[20] M. Bachar, L. Zidane, and A. Rochdi, "Ethno-medicinal and traditional phytotherapy of plants used in bouhachem natural regional park "Rif of Morocco" -case of tazroute district-," Journal of Materials and Environmental Science, vol. 7, no. 11, pp. 4175-4204, 2018.

[21] J. Bellakhdar, Contribution à l'étude de la pharmacopée traditionnelle au Maroc: la situation actuelle, les produits, les sources du savoir (enquête ethnopharmacologique de terrain réalisée de 1969 à 1992), Université de Metz, Metz, France, 1997.

[22] A. Ziyyat, A. Legssyer, H. Mekhfi, A. Dassouli, M. Serhrouchni, and W. Benjelloun, "Phytotherapy of hypertension and diabetes in oriental Morocco," Journal of Ethnopharmacology, vol. 58, no. 1, pp. 45-54, 1997.

[23] H. Jouad, M. Haloui, H. Rhiouani, J. El Hilaly, and M. Eddouks, "Ethnobotanical survey of medicinal plants used for the treatment of diabetes, cardiac and renal diseases in the North centre region of Morocco (Fez-Boulemane)," Journal of Ethnopharmacology, vol. 77, no. 2-3, pp. 175-182, 2001.

[24] J. El-Hilaly, M. Hmammouchi, and B. Lyoussi, "Ethnobotanical studies and economic evaluation of medicinal plants in Taounate province (Northern Morocco)," Journal of Ethnopharmacology, vol. 86, no. 2-3, pp. 149-158, 2003.

[25] M. Rhattas, A. Douira, and L. Zidane, "Étude ethnobotanique des plantes médicinales dans le Parc National de Talassemtane (Rif Occidental du Maroc)," Journal of Applied Biosciences, vol. 97, pp. 9187-9211, 2016.

[26] H. N. Mrabti, N. Jaradat, and M. R. Kachmar, "Integrative herbal treatments of diabetes in Beni Mellal region of Morocco," Journal of integrative medicine, vol. 17, no. 2, pp. 93-99, 2019.

[27] A. Khabbach, M. Libiad, A. Ennabili, and D. Bousta, "Medicinal and cosmetic use of plants from the province of Taza, Northern Morocco," Boletin Latinoamericano y del Caribe de Plantas Medicinales y Aromaticas, vol. 11, no. 1, pp. 46-60, 2012.

[28] S. Mariotto, A. R. Ciampa, and A. C. de Prati, "Aqueous extract of Arbutus unedo inhibits STAT1 activation in human breast cancer cell line MDA-MB-231 and human fibroblasts through SHP2 activation," Medicinal Chemistry, vol. 4, no. 3, pp. 219-228, 2012.

[29] S. Mariotto, E. Esposito, and R. Di Paola, "Protective effect of Arbutus unedo aqueous extract in carrageenan-induced lung inflammation in mice," Pharmacological Research, vol. 57, no. 2, pp. 110-124, 2008.

[30] S. Fortalezas, L. Tavares, and R. Pimpao, "Antioxidant properties and neuroprotective capacity of strawberry tree fruit (Arbutus unedo)," Nutrients, vol. 2, no. 2, pp. 214-229, 2010.

[31] I. Oliveira, V. Coelho, R. Baltasar, J. A. Pereira, and P. Baptista, "Scavenging capacity of strawberry tree (Arbutus unedo L.) leaves on free radicals," Food and Chemical Toxicology: An International Journal Published for the British Industrial Biological Research Association, vol. 47, no. 7, pp. 1507-1511, 2009.

[32] E. J. Carcache-Blanco, M. Cuendet, and E. J. Park, "Potential cancer chemopreventive agents from Arbutus unedo," Natural Product Research, vol. 20, no. 4, pp. 327-334, 2006.

[33] K. Pallauf, J. C. Rivas-Gonzalo, M. D. del Castillo, M. P. Cano, and S. de Pascual-Teresa, "Characterization of the antioxidant composition of strawberry tree (Arbutus unedo L.) fruits," Journal of Food Composition and Analysis, vol. 21, no. 4, pp. 273-281, 2008.

[34] M. A. Diba, J. Paolini, and M. Bendahou, "Chemical composition of fatty acid and unsaponifiable fractions of leaves, stems and roots of Arbutus unedo and in vitro antimicrobial activity of unsaponifiable extracts," Natural product communications, vol. 5, no. 7, pp. 1085-1090, 2010.

[35] D. R. Pavlovic, S. Brankovic, N. Kovacevic, D. Kitic, and S. Veljkovic, "Comparative study of spasmolytic properties, antioxidant activity and phenolic content of Arbutus unedo 
from Montenegro and Greece," Phytotherapy Research: PT, vol. 25, no. 5, pp. 749-754, 2011.

[36] A. Pabuccuoglu, B. Kivcak, M. Bas, and T. Mert, "Antioxidant activity of Arbutus unedo leaves," Fitoterapia, vol. 74, no. 6 , pp. 597-599, 2003.

[37] M. El Haouari, J. J. Lopez, H. Mekhfi, J. A. Rosado, and G. M. Salido, "Antiaggregant effects of Arbutus unedo extracts in human platelets," Journal of Ethnopharmacology, vol. 113, no. 2, pp. 325-331, 2007.

[38] M. G. Miguel, M. L. Faleiro, A. C. Guerreiro, and M. D. Antunes, "Arbutus unedo L: chemical and biological properties," Molecules, vol. 19, no. 10, pp. 15799-15823, 2014.

[39] J. Sic Zlabur, S. Bogdanovic, S. Voca, and M. Skendrovic Babojelic, "Biological potential of fruit and leaves of strawberry tree (Arbutus unedo L.) from Croatia," Molecules, vol. 2521 pages, 2020.

[40] I. Erkekoglou, N. Nenadis, E. Samara, and F. T. Mantzouridou, "Functional teas from the leaves of Arbutus unedo: phenolic content, antioxidant activity, and detection of efficient radical scavengers," Plant Foods for Human Nutrition, vol. 72, no. 2, pp. 176-183, 2017.

[41] M. Bnouham, F. Z. Merhfour, A. Legssyer, H. Mekhfi, S. Maallem, and A. Ziyyat, "Antihyperglycemic activity of Arbutus unedo, Ammoides pusilla and Thymelaea hirsuta," Die Pharmazie, vol. 62, no. 8, pp. 630-632, 2007.

[42] S. Afkir, T. B. Nguelefack, and M. Aziz, "Arbutus unedo prevents cardiovascular and morphological alterations in L-NAME-induced hypertensive rats Part I: cardiovascular and renal hemodynamic effects of Arbutus unedo in L-NAME-induced hypertensive rats," Journal of Ethnopharmacology, vol. 116, no. 2, pp. 288-295, 2008.

[43] A. Ziyyat, H. Mekhfi, and M. Bnouham, "Arbutus unedo induces endothelium-dependent relaxation of the isolated rat aorta," Phytotherapy Research: PT, vol. 16, no. 6, pp. 572-575, 2002.

[44] M. El Haouari and H. Mekhfi, "Anti-platelet aggregation effects of extracts from Arbutus unedo leaves," Plant Science Today, vol. 4, no. 2, pp. 68-74, 2017.

[45] H. Mekhfi, M. El Haouari, and A. Legssyer, "Platelet antiaggregant property of some Moroccan medicinal plants," Journal of Ethnopharmacology, vol. 94, no. 2-3, pp. 317-322, 2004.

[46] M. Bnouham, F. Z. Merhfour, A. Ziyyat, M. Aziz, A. Legssyer, and H. Mekhfi, "Antidiabetic effect of some medicinal plants of Oriental Morocco in neonatal non-insulin-dependent diabetes mellitus rats," Human \& Experimental Toxicology, vol. 29, no. 10, pp. 865-871, 2010.

[47] A. Legssyer, A. Ziyyat, and H. Mekh, "Tannins and catechin gallate mediate the vasorelaxant effect of Arbutus unedo on the rat isolated aorta," Phytotherapy Research: PT, vol. 18, no. 11, pp. 889-894, 2004.

[48] H. Mekhfi, M. ElHaouari, M. Bnouham, M. Aziz, A. Ziyyat, and A. Legssyer, "Effects of extracts and tannins from Arbutus unedo leaves on rat platelet aggregation," Phytotherapy Research: PT, vol. 20, no. 2, pp. 135-139, 2006.

[49] A. Ziyyat and E.-H. Boussairi, "Cardiovascular effects of Arbutus unedo L. in spontaneously hypertensive rats," Phyther Res, vol. 12, pp. 110-113, 1998.

[50] H. N. Mrabti, N. Jaradat, and I. Fichtali, "Separation, identification, and antidiabetic activity of catechin isolated from Arbutus unedo L. Plant roots," Plants, vol. 72 pages, 2018.

[51] R. Delgado-Pelayo, L. Gallardo-Guerrero, and D. HorneroMendez, "Carotenoid composition of strawberry tree
(Arbutus unedo L.) fruits," Food Chemistry, vol. 199, pp. 165-175, 2016.

[52] C. J. Lopez, C. Caleja, M. A. Prieto, M. F. Barreiro, L. Barros, and I. Ferreira, "Optimization and comparison of heat and ultrasound assisted extraction techniques to obtain anthocyanin compounds from Arbutus unedo L. Fruits," Food Chemistry, vol. 264, pp. 81-91, 2018.

[53] B. Kivcak and T. Mert, "Quantitative determination of alphatocopherol in Arbutus unedo by TLC-densitometry and colorimetry," Fitoterapia, vol. 72, no. 6, pp. 656-661, 2001.

[54] D. F. Fonseca, A. C. Salvador, and S. A. Santos, "Bioactive phytochemicals from wild Arbutus unedo L. Berries from different locations in Portugal: quantification of lipophilic components," International Journal of Molecular Sciences, vol. 16, no. 6, pp. 14194-14209, 2015.

[55] R. Vidrih, J. Hribar, Ž. Prgomet, and N. Poklar Ulrih, “The physico-chemical properties of strawberry tree (Arbutus unedo L.) fruits," Croatian Journal of Food Science and Technology, vol. 5, no. 1, pp. 29-33, 2013.

[56] F. A. Ayaz, M. Kucukislamoglu, and M. Reunanen, "Sugar, nonvolatile and phenolic acids composition of strawberry tree (Arbutus Unedo L. Var. Ellipsoidea) fruits," Journal of Food Composition and Analysis, vol. 13, pp. 171-177, 2000.

[57] M. L. C. M. M. Alarcao-E-Silva, A. E. B. Leitao, H. G. Azinheira, and M. C. A. Leitao, "The Arbutus berry: studies on its color and chemical characteristics at two mature stages," Journal of Food Composition and Analysis, vol. 14, pp. 27-35, 2001.

[58] A. M. Pawlowska, M. De Leo, and A. Braca, "Phenolics of Arbutus unedo L. (Ericaceae) fruits: identification of anthocyanins and gallic acid derivatives," Journal of Agricultural and Food Chemistry, vol. 54, no. 26, pp. 10234-10238, 2006.

[59] Z. Males, M. Plazibat, V. B. Vundac, and I. Zuntar, "Qualitative and quantitative analysis of flavonoids of the strawberry tree - Arbutus unedo L. (Ericaceae)," Acta Pharmaceutica, vol. 56, no. 2, pp. 245-250, 2006.

[60] F. Jamila and E. Mostafa, "Ethnobotanical survey of medicinal plants used by people in Oriental Morocco to manage various ailments," Journal of Ethnopharmacology, vol. 154, no. 1, pp. 76-87, 2014.

[61] A. Bouyahya, J. Abrini, A. Et-Touys, Y. Bakri, and N. Dakka, "Indigenous knowledge of the use of medicinal plants in the North-West of Morocco and their biological activities," European Journal of Integrative Medicine, vol. 13, pp. 9-25, 2017.

[62] R. Kachkoul, T. Squalli Housseini, M. Mohim, R. El Habbani, Y. Miyah, and A. Lahrichi, "Chemical compounds as well as antioxidant and litholytic activities of Arbutus unedo L. leaves against calcium oxalate stones," Journal of integrative medicine, vol. 17, no. 6, pp. 430-437, 2019.

[63] R. Kachkoul, T. Sqalli Houssaini, R. El Habbani, Y. Miyah, M. Mohim, and A. Lahrichi, "Phytochemical screening and inhibitory activity of oxalocalcic crystallization of Arbutus unedo L. leaves," Heliyon, vol. 4, no. 12, p. e01011, 2018.

[64] H. Zitouni, L. Hssaini, and R. Ouaabou, "Exploring antioxidant activity, organic acid, and phenolic composition in strawberry tree fruits (Arbutus unedo L.) growing in Morocco," Plants, vol. 912 pages, 2020.

[65] H. El Cadi, A. El Cadi, and A. Kounnoun, "Wild strawberry (Arbutus unedo): phytochemical screening and antioxidant properties of fruits collected in northern Morocco," Arabian Journal of Chemistry, vol. 13, pp. 6299-6311, 2020. 
[66] H. Zitouni, L. Hssaini, and M. Zerhoune, "Phytochemical components and bioactivity assessment among twelve strawberry (Arbutus unedo L.) genotypes growing in Morocco using chemometrics," Foods, vol. 910 pages, 2020.

[67] H. N. Mrabti, I. Marmouzi, and K. Sayah, "Arbutus unedo L aqueous extract is associated with in vitro and in vivo antioxidant activity," Journal of Materials and Environmental Science, vol. 8, no. 1, pp. 217-224, 2016.

[68] B.-M. Ruiz-Rodríguez, P. Morales, and V. Fernández-Ruiz, "Valorization of wild strawberry-tree fruits (Arbutus unedo L.) through nutritional assessment and natural production data," Food Research International, vol. 44, pp. 1244-1253, 2011.

[69] S. Morgado, M. Morgado, A. I. Placido, F. Roque, and A. P. Duarte, "Arbutus unedo L.: from traditional medicine to potential uses in modern pharmacotherapy," Journal of Ethnopharmacology, vol. 225, pp. 90-102, 2020.

[70] K. Jurica, I. B. Karaconji, S. Segan, D. M. Opsenica, and D. Kremer, "Quantitative analysis of arbutin and hydroquinone in strawberry tree (Arbutus unedo L., Ericaceae) leaves by gas chromatography-mass spectrometry," Arhiv Za Higijenu Rada I Toksikologiju, vol. 66, no. 3, pp. 197-202, 2015.

[71] R. D. Pavlovic, B. Lakusic, Z. Doslov-Kokorus, and N. Kovacevic, "Arbutin content and antioxidant activity of some Ericaceae species," Die Pharmazie, vol. 64, no. 10, pp. 656-659, 2009.

[72] G. Arumugam, P. Manjula, and N. Paari, "A review: anti diabetic medicinal plants used for diabetes mellitus," Journal of Acute Disease, vol. 2, no. 3, pp. 196-200, 2013.

[73] J. A. Colwell and R. W. Nesto, "The platelet in diabetes: focus on prevention of ischemic events," Diabetes Care, vol. 26, no. 7, pp. 2181-2188, 2003.

[74] B. Salehi and A. Ata, "Antidiabetic potential of medicinal plants and their active components," Biomolecules, vol. 910 pages, 2019.

[75] J. L. Rios, F. Francini, and G. R. Schinella, "Natural products for the treatment of type 2 diabetes mellitus," Planta Medica, vol. 81, no. 12-13, pp. 975-994, 2018.

[76] H. N. Mrabti, K. Sayah, and N. Jaradat, "Antidiabetic and protective effects of the aqueous extract of Arbutus unedo L. in streptozotocin-nicotinamide-induced diabetic mice," Journal of Complementary \& Integrative Medicine, vol. 15, no. 3, 2018.

[77] A. Shirwaikar, K. Rajendran, C. Dinesh Kumar, and R. Bodla, "Antidiabetic activity of aqueous leaf extract of Annona squamosa in streptozotocin-nicotinamide type 2 diabetic rats," Journal of Ethnopharmacology, vol. 91, no. 1, pp. 171-175, 2004.

[78] H. N. Mrabti, M. El Abbes Faouzi, and F. M. Mayuk, "Arbutus unedo L., (Ericaceae) inhibits intestinal glucose absorption and improves glucose tolerance in rodents," Journal of Ethnopharmacology, vol. 235, pp. 385-391, 2019.

[79] M. Cubrilo-Turek, "Hypertension and coronary heart disease," EJIFCC, vol. 14, no. 2, pp. 67-73, 2003.

[80] M. El Haouari and J. A. Rosado, "Platelet signalling abnormalities in patients with type 2 diabetes mellitus: a review," Blood Cells, Molecules, and Diseases, vol. 41, no. 1, pp. 119-123, 2008.

[81] P. C. Elwood, A. D. Beswick, D. S. Sharp, J. W. Yarnell, S. Rogers, and S. Renaud, "Whole blood impedance platelet aggregometry and ischemic heart disease. The Caerphilly Collaborative Heart Disease Study," Arteriosclerosis, vol. 10, no. 6, pp. 1032-1036, 1990.
[82] N. E. Barrett, L. Holbrook, and S. Jones, "Future innovations in anti-platelet therapies," British Journal of Pharmacology, vol. 154, no. 5, pp. 918-939, 2008.

[83] P. C. Redondo, I. Jardin, J. M. Hernandez-Cruz, J. A. Pariente, G. M. Salido, and J. A. Rosado, "Hydrogen peroxide and peroxynitrite enhance $\mathrm{Ca} 2+$ mobilization and aggregation in platelets from type 2 diabetic patients," Biochemical and Biophysical Research Communications, vol. 333, no. 3, pp. 794-802, 2005.

[84] J. A. Rosado, P. C. Redondo, G. M. Salido, E. Gomez-Arteta, S. O. Sage, and J. A. Pariente, "Hydrogen peroxide generation induces pp60src activation in human platelets: evidence for the involvement of this pathway in store-mediated calcium entry," Journal of Biological Chemistry, vol. 279, no. 3, pp. 1665-1675, 2004.

[85] L. A. Pham-Huy, H. He, and C. Pham-Huy, "Free radicals, antioxidants in disease and health," International journal of biomedical science: IJBS, vol. 4, no. 2, pp. 89-96, 2008.

[86] Y. Z. Fang, S. Yang, and G. Wu, "Free radicals, antioxidants, and nutrition," Nutrition, vol. 18, no. 10, pp. 872-879, 2002.

[87] A. Bouyahya, N. El Moussaoui, J. Abrini, Y. Bakri, and N. Dakka, "Determination of phenolic contents, antioxidant and antibacterial activities of strawberry tree (Arbutus unedo L.) leaf extracts," British Biotechnology Journal, vol. 14, no. 3, pp. 1-10, 2016.

[88] E. Navas, "Problems associated with potential massive use of antimicrobial agents as prophylaxis or therapy of a bioterrorist attack," Clinical microbiology and infection: The Official Publication of the European Society of Clinical Microbiology and Infectious Diseases, vol. 8, no. 8, pp. 534-539, 2002.

[89] C. D. Romero, S. F. Chopin, G. Buck, E. Martinez, M. Garcia, and L. Bixby, "Antibacterial properties of common herbal remedies of the southwest," Journal of Ethnopharmacology, vol. 99, no. 2, pp. 253-257, 2005.

[90] A. El ouarti, A. C. Haouat, and H. Sqalli, "Extra- and intracellular antimycobacterial activity of Arbutus unedo L," African Journal of Microbiology Research, vol. 6, no. 6, pp. 1283-1290, 2012.

[91] S. Chiheb, N. Guessous-Idrissi, and A. Hamdani, "Leishmania tropica cutaneous leishmaniasis in an emerging focus in North Morocco: new clinical forms," Annales de Dermatologie et de Vénéréologie, vol. 126, no. 5, pp. 419-422, 1999.

[92] A. El Aasri, Y. El Madhi, M. Najy, O. El Rhaouat, and D. Belghyti, "Epidemiology of cutaneous leishmaniasis in sidi kacem province, northwestern Morocco (2006-2014)," Asian Pacific J Trop Dis, vol. 6, no. 10, pp. 783-786, 2016.

[93] A. Bouyahya, A. Et-Touys, N. Dakka, H. Fellah, J. Abrini, and Y. Bakri, "Antileishmanial potential of medicinal plant extracts from the North-West of Morocco," Beni-Suef University Journal of Basic and Applied, vol. 7, pp. 50-54, 2018.

[94] A. Bouyahya, Y. Bakri, A. Et-Touys, I. C. C. Assemian, J. Jamal Abrini, and N. Dakka, "In vitro antiproliferative activity of selected medicinal plants from the North-West of Morocco on several cancer cell lines," European Journal of Integrative Medicine, vol. 18, pp. 23-29, 2020.

[95] E. N. Taylor, M. J. Stampfer, and G. C. Curhan, "Obesity, weight gain, and the risk of kidney stones," Journal of the American Medical Association, vol. 293, no. 4, pp. 455-462, 2005.

[96] L. A. Ruml, M. S. Pearle, and C. Y. Pak, "Medical therapy, calcium oxalate urolithiasis," Urologic Clinics of North America, vol. 24, no. 1, pp. 117-133, 1997. 
[97] A. M. Freitas, N. Schor, and M. A. Boim, "The effect of Phyllanthus niruri on urinary inhibitors of calcium oxalate crystallization and other factors associated with renal stone formation," BJU International, vol. 89, no. 9, pp. 829-834, 2002.

[98] V. Butterweck and S. R. Khan, "Herbal medicines in the management of urolithiasis: alternative or complementary?" Planta Medica, vol. 75, no. 10, pp. 1095-1103, 2009.

[99] Y. S. Zhong, C. H. Yu, H. Z. Ying, Z. Y. Wang, and H. F. Cai, "Prophylactic effects of Orthosiphon stamineus Benth. extracts on experimental induction of calcium oxalate nephrolithiasis in rats," Journal of Ethnopharmacology, vol. 144, no. 3, pp. 761-767, 2012.

[100] L. Baddade, M. Berkani, M. Oubenali, A. Ben Ali, and M. Mbarki, "Activité anti-lithiasique des extraits aqueux des fruits de l'Arbutus Unedo et de l'amande de Zizyphus Lotus," International Journal of Innovation and Applied Studies, vol. 25, no. 3, pp. 1100-1106, 2019.

[101] J. A. Guerrero, M. L. Lozano, J. Castillo, O. BenaventeGarcia, V. Vicente, and J. Rivera, "Flavonoids inhibit platelet function through binding to the thromboxane A2 receptor," Journal of Thrombosis and Haemostasis: JTH, vol. 3, no. 2, pp. 369-376, 2005.

[102] J. M. Kim and H. S. Yun-Choi, "Anti-platelet effects of flavonoids and flavonoid-glycosides from Sophora japonica," Archives of Pharmacal Research, vol. 31, no. 7, pp. 886-890, 2008.

[103] D. Rein, T. G. Paglieroni, and T. Wun, "Cocoa inhibits platelet activation and function," American Journal of Clinical Nutrition, vol. 72, no. 1, pp. 30-35, 2000.

[104] Y. Sagesaka-Mitane, M. Miwa, and S. Okada, "Platelet aggregation inhibitors in hot water extract of green tea," Chemical and Pharmaceutical Bulletin, vol. 38, no. 3, pp. 790-793, 1990.

[105] Y. Huang, J. Hao, and D. Tian, "Antidiabetic activity of a flavonoid-rich extract from Sophora davidii (franch.) skeels in KK-ay mice via activation of AMP-activated protein kinase," Frontiers in Pharmacology, vol. 9, p. 760, 2018.

[106] S. K. Mantena, M. S. Baliga, and S. K. Katiyar, "Grape seed proanthocyanidins induce apoptosis and inhibit metastasis of highly metastatic breast carcinoma cells," Carcinogenesis, vol. 27, no. 8, pp. 1682-1691, 2006.

[107] S. J. Duffy, J. F. Keaney, and M. Holbrook, "Short- and longterm black tea consumption reverses endothelial dysfunction in patients with coronary artery disease," Circulation, vol. 104, no. 2, pp. 151-156, 2001.

[108] H. Orch, A. Douira, and L. Zidane, "Étude ethnobotanique des plantes médicinales utilisées dans le traitement du diabète, et des maladies cardiaques dans la région d'Izarène (Nord du Maroc)," Journal of Applied Biosciences, vol. 86, pp. 7940-7956, 2015. 